\title{
Museo Nacional y museos privados en Guatemala: patrimonio y patrimonialización. Un siglo de intentos y frustraciones
}

\author{
por \\ Marta Elena Casaús Arzú ${ }^{1}$ \\ Universidad Autónoma de Madrid
}

A lo largo del siglo XIX la mayoría de los países de América Latina impulsaron la creación de museos nacionales (que incluían la propia arqueología, antropología y etnología) como uno de los vehículos para promover la construcción de los estados nacionales y para sentar las bases de la homogenización de la nación, entendiendo esas instituciones como lugares destinados a la educación cívica de los ciudadanos, la recuperación de la memoria y la construcción de un pasado común que permitieran la formación de una identidad nacional. El caso de Guatemala, sin embargo, destaca por su singularidad y su tendencia a ir en dirección inversa: negar el pasado histórico maya, no aceptar el principio de nación homogénea y dejar en manos de la Sociedad Económica de Amigos del País, en el siglo XIX, la construcción del primer Museo Nacional y, posteriormente, en manos de la iniciativa privada la construcción de los museos de arqueología, generándose con ello un proceso de patrimonialización de la cultura y, al mismo tiempo, de privatización del patrimonio nacional.

Palabras Clave: Museo nacional; museo público; museo privado; memoria; patrimonio; nación; Guatemala.

\section{INTRODUCCIÓN}

En América Latina la construcción de los grandes museos nacionales constituyó un elemento inestimable para la construcción de un pasado común, de una historia y de una memoria consensuada ${ }^{2}$. Como opinan Andermann (2000)

1 Este trabajo se inscribe en el proyecto de investigación «Museos, memoria y antropología: América y otros espacios de colonización», financiado por el Ministerio de Ciencia e Innovación del Gobierno de España (referencia: HAR2009-10107).

2 Sobre este tema, véase Quijada, Bernand y Schneider, 2001. 
y Levin (2006), los museos nacionales fueron un punto de arranque para la construcción de los estados nacionales porque inventaron la tradición, reconstruyeron un pasado idealizado y recrearon héroes y símbolos patrios para la fundación de las nuevas naciones latinoamericanas. El caso de México, Brasil o Argentina así parecen indicarlo ${ }^{3}$. En este sentido casi todos los museos nacionales del siglo XIX y principios del XX tendrían un componente de exaltación nacionalista, que buscaba las esencias de la patria y de la nación ${ }^{4}$. Sin embargo en Guatemala no hay indicios de este componente nacionalista ni de búsqueda de un pasado común a lo largo del siglo XIX y la presencia del Estado en el proceso de constitución de los museos nacionales es muy tardía, por razones hasta ahora poco estudiadas.

Coincidimos con Bustamante que el objetivo de la fundación de los museos nacionales en Europa y en América Latina obedece a dos formas distintas de recuperar la memoria.

La contrastación entre los casos europeos y latinoamericanos descubre, en primer lugar, algo bastante evidente: que los museos antropológicos — según el continente- se fundamentan en dos tipos distintos de memoria. Para los europeos se trata de una memoria colonizadora y de expansión (expresada en la recolección de objetos que se categorizan como exóticos) y para los americanos se trata de una memoria nacional, en la que se combina la condición de colonizado — frente a Europa - con la de colonizador - frente a las poblaciones indígenas y territorios propios - expresadas en la recolección de objetos que se categorizan como autóctonos, todo lo cual implica, naturalmente, políticas y discursos diferenciados ${ }^{5}$.

En este sentido Bustamante coincide con Anderman (2000), Levin (2006) y Earle (2007) sobre la importancia de los museos en la definición de la identidad nacional, en la recreación de la nación y la consolidación de los estados nacionales de fines del XIX. Esa exaltación de un nacionalismo patrio cuyo ejemplo más emblemático fue la creación y evolución del Museo Nacional de México, que luego sería el Nacional de Antropología de México, y que parece ser una tendencia común a casi todas las repúblicas latinoamericanas, no se produjo en Guatemala, ni en el tiempo ni en la intencionalidad del Estado ni en la voluntad de sus elites políticas e intelectuales de forjar patria.

Desconocemos la razón de esta «anormalidad histórica», que podríamos achacar en un principio a la especificidad centroamericana. Sin embargo, en el

3 Morales, 2007. Earle, 2007.

4 Para Luis Gerardo Morales el Museo Nacional de Arqueología y Antropología en México, se diseña pedagógicamente como un Museo Templo de la Nación en donde se crea y se justifica el vínculo entre el museo, la patria porfirista y el nacionalismo revolucionario en la búsqueda de una identidad histórica común. Véase Morales, 2003.

5 Bustamante, 2010 y 2012. 
resto de la región, los museos nacionales se crearon a finales del siglo XIX por mandato de los gobiernos liberales de turno ${ }^{6}$, lo cual pone aún más en evidencia la excepcionalidad del caso guatemalteco, motivada en unas causas que trataremos de exponer a lo largo de este trabajo.

Comenzar dejando constancia de esa excepcionalidad en el caso guatemalteco, de alguna manera nos ayuda a explicar por qué se produjo una fundación tan tardía del Museo Nacional de Arqueología y Etnología ${ }^{7}$ (1931) y del Museo Nacional de Historia y Bellas Artes (1934), y por qué esa falta de voluntad política de las elites de poder hizo que fueran las elites económicas, las que patrimonializaran la cultura y el patrimonio nacional.

Lo que parece evidente, a tenor de los debates que se produjeron en la prensa con motivo del primer intento de creación por parte del Estado del Museo Nacional de Arqueología y Etnología en 1922 y de la creación del Instituto de Arqueología, Antropología e Historia en 1936 y 1937, es que hubo una fuerte resistencia por parte de las elites de poder que se basaba en un reconocimiento muy escaso del indígena como parte de la nación, a pesar de los enormes descubrimientos arqueológicos que se venían realizando desde principios de siglo en Tikal, Quiriguá, Yaxhá y un gran número de sitios excavados por universidades e instituciones privadas norteamericanas. Los agrios debates que se produjeron entonces muestran con claridad que no se quería considerar a los indígenas actuales como parte de la civilización maya del pasado $\mathrm{y}$, mucho menos, como parte constitutiva en el presente de la nacionalidad guatemalteca ${ }^{8}$.

La historia de la fundación del Museo de Arqueología y Etnología de Guatemala, seguida de un breve repaso de los numerosos museos privados, de excepcional calidad, en manos de miembros de las principales redes familiares del país, así como de grandes extensiones del patrimonio nacional arqueológico, en manos de fundaciones internacionales, nos servirán para probar nuestras hipótesis de partida.

6 En El Salvador, el Museo Nacional de Antropología «David J. Guzmán» fue inaugurado el 9 de octubre de 1883, durante la presidencia de Manuel Zaldívar; en Nicaragua se fundó en 1897 el Museo de Historia Natural y Científica que cien años más tarde se convertiría en el Museo Nacional de Nicaragua «Dioclesiano Cháves», y en Costa Rica en 1887, bajo la presidencia de Bernardo Soto, se creó el Museo Nacional que contiene colecciones de historia natural, artística y arqueológica.

7 Ningún museo en América Central tiene una consolidación gubernativa tan tardía. Teniendo en cuenta que el área centroamericana con mayor riqueza de testimonios de la antigua civilización maya está en Guatemala y en Honduras y que el resto de los países no cuenta con grandes vestigios arqueológicos de este tipo, sin embargo, ellos sí fundaron sus museos y los dotaron de presupuesto.

8 Casaús Arzú, 2008a. 
I Parte. El Museo Nacional de Arqueología y Etnología: ReSEÑA HISTÓRICA DE UN SIGLO DE INTENTOS FUNDACIONALES

A lo largo del siglo XIX y principios del XX hubo en Guatemala sucesivos intentos, todos ellos frustrados, de fundar un museo sobre la historia, antropología y arqueología patrias.

El primer intento del que tenemos noticia se produjo en 1831 y se debe al gobierno liberal de Mariano Gálvez (1831-1838). En un decreto-ley del 24 de octubre de 1831, el Estado se comprometía a crear un museo nacional en el que «se recogieran toda especie de curiosidades científicas y de las artes». Sin embargo un año más tarde la iniciativa ya parece haber fracasado, habiendo un nuevo intento fundacional en 1851. Sin embargo, el proyecto solo parece concretarse en 1864, cuando la Sociedad Económica de Amigos del País (SEAP) tomó la decisión de constituir el Museo Nacional con fondos propios y sin ayuda del gobierno 9 .

El 7 de enero de 1866 se inauguró el Museo con la presencia de varios ministros y del arzobispo metropolitano, Francisco de Paula García Peláez. El Museo estaba compuesto entonces por varios departamentos, Etnográfico, Historia Natural, Mineralogía y una biblioteca; y se encontraba alojado en las dependencias de la propia SEAP. A juicio de Luján, la sección de etnología podía asemejarse a lo que fueron los museos de antropología de otros países, que contaban con una serie de objetos labrados en piedra, barro y madera, así como vasijas y objetos de jade y «yugos ceremoniales». Llama la atención el hecho de que la mayoría de los objetos fueran donados por los socios fundadores de la institución, como un dintel de madera de Tikal, un vaso de jade o una cabeza de piedra regalada por el presidente de Honduras, que procedía del Museo Nacional Vicente Cerna y anteriormente de Copán. Entre los documentos históricos se menciona la copia de la edición del Popol Vuh, de la Historia de los Quichés y Anales Cachiqueles, el Libro segundo y tercero del Cabildo de Guatemala, todos propiedad de la SEAP ${ }^{10}$.

La biblioteca vinculada al departamento etnográfico contaba con un importante catálogo en el que figuraban las obras de Acosta, Remesal, Solórzano Pereira y Domingo de Juarros, así como con una extensa colección de periódicos centroamericanos, la colección Payés del siglo XIX y diversos documentos manuscritos ${ }^{11}$.

9 En el boletín de la SEAP se informa de la cantidad de 1 dólar, 879 con 6 reales y 3 cuartillos como aportación privada de los socios. Luján Muñoz, 1973: 174.

10 Luján Muñoz, 1973: 176.

11 Luján Muñoz, 1973: 177. 
Resulta interesante resaltar que el cargo de director del museo recaía sobre los socios de la SEAP y era de carácter voluntario, sin sueldo. El crecimiento del museo obligó a la Sociedad a ocupar un edificio aledaño en 1875 y remodelarlo para poder albergar las piezas. Los costes fueron sufragados en su totalidad por la SEAP. En ninguno de sus boletines figura la existencia de aportación alguna del gobierno central, ni siquiera en la consecución de objetos arqueológicos ni de recursos humanos. En 1876, uno de los socios propuso que Guatemala asistiera a una de las exposiciones universales, pero desistió al no contar con ningún apoyo del gobierno. Ese mismo año de 1876 un socio fundador de la SEAP, diputado a su vez del partido liberal, Antonio Batres Jáuregui, pidió por primera vez a los jefes políticos que cooperaran con el museo y que ofrecieran a la institución sus piezas arqueológicas y etnográficas, «previo pago de las mismas». Sin embargo, por lo que se desprende de los boletines de la SEAP, las mayores aportaciones siguieron procediendo de los socios ${ }^{12}$.

Unos años más tarde, a pesar del esfuerzo de la SEAP por mantener y agrandar el museo, el gobierno liberal de Justo Rufino Barrios por decreto del 25 de abril de 1881 clausuró la Sociedad Económica de Amigos del País y, con ella también el museo, y solicitó que las piezas de la institución pasaran al Ministerio de Fomento. El edificio que albergaba el museo pasó a convertirse en local para la Asamblea Legislativa (y actualmente del Congreso de la República).

Según Luján, el cierre intempestivo se debió a las pugnas existentes entre conservadores y liberales y estuvo motivado por la enorme preponderancia que la SEAP tenía en la vida pública y cultural del país. Se desconoce el destino que tuvieron las piezas, hasta que en 1898 surgió una nueva iniciativa de museo, esta vez un verdadero Museo Nacional, que fue ubicado en el Palacio de La Reforma, destruido por los terremotos de 1917 y 1918. Parece significativo que, después del terremoto, sí se recuperan los departamentos de zoología y mineralogía en el Parque de La Aurora y que las piezas arqueológicas y etnológicas se perdieran para el acceso público o incluso quedaran enterradas por casi una década ${ }^{13}$.

12 Véase La Sociedad Económica, tomo IV, n. ${ }^{\circ} 39$ (30 de julio de 1876), Guatemala, Imprenta de la Paz, 1876: 1; tomo IV, n. ${ }^{\circ} 44$ (3 de septiembre de 1876): 1 y tomo IV, n. $^{\circ} 46$ (23 de septiembre de 1876): 1, citados por Luján Muñoz, 1973: 184. En el boletín tomo VI, n. ${ }^{\circ} 6$ (14 de mayo de 1880): 1, se hace referencia al donativo de «un fragmento de madera de las ruinas de Tikal» realizado por el socio Salvador Valenzuela y que Luján Muñoz supone pudo haberse tratado del fragmento de un dintel de Tikal, Luján Muñoz, 1973: 184, glosa 40.

13 Durante la década de 1920 hubo varias iniciativas para crear el nuevo museo, pero todas ellas fueron infructuosas. El 14 de julio de 1922, el General José María Orellana emite el acuerdo 791 y el 7 de mayo de 1925, el Decreto 1376, ambos dentro de las reformas que com- 
Llama la atención esa dejación de responsabilidades por parte del Estado en lo que se refiere a la conservación del patrimonio nacional, así como en la construcción de un proyecto de Estado nacional a través de la exhibición de su pasado histórico, sobre todo en un país, con un acervo arqueológico tan rico que, para esa época, ya estaba siendo descubierto y ampliamente difundido por arqueólogos y universidades norteamericanas ${ }^{14}$.

El contexto cultural e intelectual de Guatemala en la década de 1930 y la refundación del Museo Nacional

En el ambiente cultural guatemalteco de las décadas de 1920 y 1930 se produjo el despertar del interés por la cultura maya arqueológica y por el estudio de sus vestigios en las comunidades indígenas del presente. El descubrimiento de Tikal y Uaxactum unas décadas antes, los múltiples viajes de Morley, entre 1914, 1922 y 1937, las expediciones científicas del Instituto Carnegie desde 1907 para explorar la región del Petén, el descubrimiento de la epigrafía, de la astronomía y de la cosmogonía mayas, así como la presencia en Guatemala de antropólogos de renombre, como Melvin Tumin, Manuel Gamio, Sol Tax, Benjamín Paul y Robert Redfield, que estudiaban la pervivencia de las comunidades indígenas, generaron un nuevo interés por el estudio de la sociología, la arqueología y de la antropología cultural en Guatemala ${ }^{15}$.

Pero también sentaron las bases de lo que se convertiría en una las mayores polémicas en la prensa de 1936-1937 acerca del pasado de la cultura maya y del presente de los indígenas guatemaltecos; polémica que, sin duda, tiene re-

prendería la Ley Reglamentaria del Museo Nacional, sin que sepamos a ciencia cierta, las razones por las cuales el Museo no se puso en marcha.

14 La Institución Carnegie llegó a Guatemala en torno a 1907, unos años más tarde que el Museo Peabody de Harvard en 1905, quien envió a los arqueólogos Teoberto Maler y Alfredo Tozzer a explorar Tikal y Nankín. Fueron las investigaciones del Instituto Carnegie, al mando de Silvanus Morley, quienes obtuvieron los mayores éxitos en las exploraciones de Petén, Quiriguá, Uaxactum, Tikal y Piedras Negras. En 1916, se firmó el primer convenio al que le siguieron otras licencias exclusivas de explotación de Piedras Negras, Uaxactum, Tayasal, en 1922, sin ninguna contraprestación para el gobierno de Guatemala.

15 Véase el interesante estudio sobre la generación pionera de antropólogos en los años 1930 y 1940 de Gutiérrez Mendoza, 2000. Según Gutiérrez Mendoza, los intelectuales que firman la Declaración Indigenista de Patzcuátaro en 1941 y que forman el primer grupo de indigenistas de Guatemala son: David Vela, Jorge Luis Arriola, Mario Monteforte Toledo, Flavio Herrera y José Castañeda, que tuvieron mucho que ver con la configuración del nuevo museo y su refundación, especialmente la figura de Antonio Goubaud Carrera. Véase además Gutiérrez Mendoza, 2009 y 2010. 
lación directa con hechos como el descubrimiento de la Estela 26 en Uaxactum, la traducción del libro de Morley sobre las ruinas de Quiriguá por Alfredo Sierra Valle, la creación de la cátedra de Estudios Mayas, la traducción comentada del Popol Vuj de Adrián Recinos y las excavaciones realizadas por las universidades de Pensilvania, Filadelfia y el Instituto Carnegie ${ }^{16}$. El punto de partida es un artículo en El Imparcial escrito por un intelectual de renombre que vivía fuera de Guatemala, Alfredo Sierra Valle. En él planteaba la necesidad de crear una cátedra para el estudio de la historia maya y lo justificaba, entre otras razones, por la enorme importancia que esa historia tenía para el conocimiento de «nuestro pasado» y «la importancia que han tenido los descubrimientos de las ruinas de Quiriguá»». A esta siguieron otras dos propuestas, complementarias y más arriesgadas, de Ramón Blanco y de Antonio Goubaud, abogando por una Facultad de Antropología Arqueología y Etnología ${ }^{17}$.

Esta eclosión de publicaciones y el descubrimiento de los sitios arqueológicos mayas, así como los intentos frustrados de la creación del Museo Nacional de Arqueología y Etnología, pusieron de nuevo sobre el tapete la problemática indígena y contribuyeron enormemente a la profusión de artículos y libros en los que se manifestaban las opiniones más variadas: unas, de admiración por esta civilización y sus vestigios; otras, de curiosidad y extrañeza por no poder explicarse la relación existente entre «esos Mayas del pasado» y los «indios» actuales «degenerados e inferiores»; y otras, las menos, trataban de reescribir la historia colonial y la historia del siglo XIX, buscando los referentes de la cultura indígena en el presente y su incidencia en la cultura nacional.

Resulta interesante observar cómo el historiador y ministro de Educación, Antonio Villacorta (1879-1962), que escribió sobre el mestizaje y resaltó el pasado maya como forma de construir una historia nacional, sostuviera durante el período de 1927 a 1934 que la civilización maya pertenecía al pasado y que los indios actuales eran «una raza enferma y degenerada», susceptible de ser mejorada por la inmigración o el mestizaje, presupuestos que en esos momentos compartían otros miembros del gobierno de Jorge Ubico Castañeda como Carlos Samayoa Chinchilla y Carlos Federico Mora.

Posiblemente el fenómeno ideológico-político más importante que se produjo durante las dictaduras cabrerista (1898-1920) y ubiquista (1931-1944), fue el del fortalecimiento del Estado y el debilitamiento de la nación. Durante el periodo de estas dictaduras liberales, el indígena pasó a ser objeto de curio-

16 Véanse la gran cantidad de artículos de El Imparcial que tratan el tema: XV, 5056 (Guatemala, 1936); XV, 5071 (Guatemala: 1936); XV, 5131 (Guatemala, 1936).

17 Véanse Sierra Valle, 1936; así como otras iniciativas de Blanco, 1936, o la propuesta más completa de Goubaud, 1936. Véase Gutiérrez Mendoza, 2009: 43 y ss. 
sidad, de interés y de sorpresa para los intelectuales. Sorpresa por su pasado histórico grandioso y por los hallazgos arqueológicos de la civilización maya que lo probaban. Curiosidad, por no entender qué relación existía entre esos mayas gloriosos y «estos indios desharrapados del presente»; cómo se produjo su decadencia y qué o quién la provocó. Puesto que ya no era válido achacársela al principio de que era una raza inferior, había que buscar nuevas causas que explicasen su decadencia actual.

La confirmación arqueológica y antropológica del pasado glorioso de la civilización maya y de sus vestigios en el presente; su difusión al gran público por la traducción de las obras de los más connotados arqueólogos, etnohistoriadores y antropólogos, removieron las conciencias de las elites intelectuales criollas y les obligó a reinventar su pasado y a buscar nuevas teorías pseudocientíficas o nuevas interpretaciones históricas que continuasen afirmando la inferioridad, degeneración o decadencia del indígena actual y que asegurasen por esa vía los mecanismos de poder existentes para mantener su estado de sumisión y sojuzgamiento. En otras palabras, el debate se produjo para buscar nuevas explicaciones que siguieran justificando el sistema de dominación y de subalternidad de los indígenas, a los cuales ya no se les necesitaba como parte integrante de la nación.

Frente a procesos como los de México y Perú, de «nacionalizar la nación» por la vía del pasado de los Incas y de los Aztecas, para lograr así «peruanizar» Perú o «mexicanizar» México, generando una ideología del mestizaje y de la hibridación cultural, el Estado guatemalteco optó por el modelo contrario: negar el pasado indígena, demostrar que no quedaba más que la decadencia o la degeneración del indígena actual; desvalorizar todos los rasgos de su cultura y tratar de borrar de la memoria histórica a la nación ${ }^{18}$.

Las voces que más sobresalieron, por la coyuntura política interna e internacional, fueron las de los intelectuales partidarios del determinismo biológico, psicológico y medio-ambiental; triunfaron personajes como Samayoa Chinchilla, Epaminondas Quintana, Federico Mora, Antonio Villacorta, todos ellos intelectuales vinculados al ubiquismo, que se empeñaron en demostrar la inferioridad del indio, su decadencia actual o su agonía vital; o, en el peor de los casos, planteaban que el maya del pasado en nada correspondía al indio del presente; y que las condiciones del medio, las causas históricas o su falta de energía vital había sido lo que provocó su «actual estado de abyección», no

18 Posición mantenida por buena parte de las elites intelectuales y políticas ubiquistas en personajes como Villacorta, Samayoa Chinchilla o Mora, todos ellos partidarios de las teorías eugenésicas. Véase Casaús, 2010b. 
siendo recuperable por ningún medio, de ahí la propuesta de su exterminio y la mejora racial.

En opinión de Gordillo, Antonio Villacorta - el historiador guatemalteco por excelencia - consideraba que solo había dos grupos sociales que habían contribuido a la formación de la nacionalidad guatemalteca, los criollos y los mestizos, representantes del «alma de la patria... urbana, culta, instruida y progresista». Los indígenas eran «una raza enferma y degenerada», rurales dedicados a la agricultura. Al igual que para otros pensadores racialistas de la época, la inmigración europea era el ideal para mejorar la raza, y los mestizos y ladinos eran la solución intermedia ${ }^{19}$.

Las tesis del exterminio y de la eugenesia, contrariamente a lo que se ha venido diciendo, estaban muy presentes en el debate público y formaban parte del discurso hegemónico. Sin duda eran sostenidas por las corrientes que más influyeron en el imaginario colectivo del ciudadano guatemalteco en su visión sobre el indio y la nación. Posiciones como las de Samayoa Chinchilla, secretario privado de la Presidencia de Ubico, así parecen indicarlo, para este autor, como para muchos otros de la generación del 20:

El indio de Guatemala, es un valioso elemento decorativo, forma parte de nuestros paisajes y en lo que respecta a su condición merece nuestro respeto humano. Pero creer que en él reside un buen factor étnico capaz de llegar a desarrollar un gran esfuerzo, como el que la vida actual requiere, me parece que es una utopía porque, el indio, cargado de conocimientos y favorecido por todas las circunstancias imaginables será siempre indio, es decir un ser huraño ante toda idea nueva, impenetrable y como sonámbulo entre el enjambre de inquietudes que acosan al hombre en su marcha hacia la conquista del futuro [...] su verdadera redención no llegará sino cuando su vieja sangre tenga oportunidad de mezclarse con representantes de raza blanca ${ }^{20}$.

Para Samayoa Chinchilla, el indio era un elemento decorativo, formaba parte de nuestro «paisaje», pero no era un individuo ni mucho menos era un ciudadano, sino que era «una sombra, un ser agónico, un sonámbulo», cuyas energías gastadas le impedían seguir viviendo, al que habría que ayudar a morir o eliminarle, porque «es un obstáculo para el desarrollo, muerto en vida al que hay que

19 Esta cita nos recuerda el planteamiento de Justo Sierra y de Molina Enríquez respecto a la estructura del México mestizo, pero también a autores guatemaltecos como Samayoa Chinchilla y Federico Mora, ambos partidarios de las tesis eugenésicas y que ocuparon varios ministerios durante los gobiernos de Orellana, Chacón y Ubico. Véase Gordillo, 2001: 135 y Casaús y García Giráldez, 2005.

${ }_{20}$ Carlos Samayoa Chinchilla era Secretario de la presidencia de Ubico y uno de los que más influyó en el dictador. Además, participó activamente en la constitución del Museo Nacional de 1931. Véase, Casaús Arzú, 2010b. 
ayudarle a morir»; y solo si no se lograba eliminarle, que sería lo deseable, habría que fusionar su sangre con «representantes de la raza blanca» ${ }^{21}$.

Es en este peculiar contexto donde surge el tercer intento guatemalteco de crear un Museo de Arqueología y Etnología, después de que se hiciera abortar en 1881 la primera iniciativa de la Sociedad Económica de Amigos del País, y de que también se malograra por los terremotos de 1917-1918 el segundo intento iniciado en 1898. Comienzaba así, el 28 de junio de 1931, la reubicación del Museo Nacional de Arqueología y Etnología en el Parque de La Aurora.

A modo de hipótesis, podemos adelantar que los frustrados intentos de creación del Museo de Arqueología y Etnología en Guatemala y su tardía aparición, guardan relación con un desinterés por parte del estado por forjar un pasado histórico y una memoria colectiva que contribuyera a crear una nación homogénea. En segundo lugar, con el afán de las elites intelectuales y económicas de patrimonializar la cultura y de privatizar el patrimonio nacional y, por último, con los intereses de las instituciones y universidades norteamericanas y europeas de controlar en su totalidad las excavaciones arqueológicas y exportar los objetos mayas a sus respectivos países para que formaran parte de sus museos. Cabe añadir, como se expondrá por extenso en la segunda parte de este trabajo, que esta forma de proceder del Estado y de las clases dominantes y compañías extranjeras, sigue siendo una práctica común de gestionar el patrimonio cultural del país.

\section{La reubicación del Museo de Arqueología y Etnología en 1931 y posibles causas para el retraso de su refundación}

La refundación del Museo Nacional de Arqueología y Etnología se produjo en 1931, durante el gobierno de Jorge Ubico Casteñeda, aunque creemos que la iniciativa no fue de este presidente, que acababa de ocupar el cargo presidencial, sino del gobierno de Lázaro Chacón González, cuyo Ministro de Cultura fue el historiador Antonio Villacorta (ministro durante las presidencias de Orellana, Chacón y Ubico).

El hecho de que Antonio Villacorta fuera Ministro de Educación durante estos tres gobiernos, y que durante su primera etapa de 1927 a 1934, haya tomado una posición clara de recuperación del pasado indígena y de exaltación

21 No está de más recordar que el mismo Samayoa Chinchilla que se expresaba de esta forma sobre los «indios» y que fue quien mantuvo la posición más dura sobre los indígenas actuales en el debate de 1937, fue a su vez uno de los fundadores del Museo Nacional de Arqueología, y su nombre aparece en el Acta constitutiva de la fundación del Museo en 1931. Véase Casaús Arzú, 2008b. 
del mestizaje y que, para tal fin, hiciera una amplia difusión del Popol Vuh y escribiera la tercera parte de su Historia de Guatemala, titulada Prehistoria e Historia Antigua de Guatemala, así como una serie de libros o folletos vinculados a la arqueología maya, junto con su hijo Carlos Villacorta que, posteriormente, fue Inspector de Monumentos Nacionales y Director del Museo en $1931^{22}$, nos da fundamento para pensar que durante esta etapa, previa al ubiquismo, ya existía una conciencia nacional por parte de algunos ministros de los gobiernos anteriores de reivindicar el pasado maya como elemento para la recuperación de la historia y la memoria nacional y existía una legislación favorable a la creación del museo con anterioridad a $1931^{23}$.

Sin embargo, sorprende el notable retraso en la refundación del Museo y el escaso esfuerzo que se hizo por llevarla a cabo. Cosa que pone de relieve el propio Carlos Villacorta en la petición del cargo de director del Museo a su padre y Ministro de Educación:

Llama la atención a los extranjeros que entienden de estas cosas, y que visitan Guatemala, el que no haya podido establecerse el Museo Nacional, cuando habiendo sido nuestro país la cuna de la civilización maya-quiché puede con tiempo y perseverancia formarse colecciones arqueológicas y etnológicas dignas de ser admiradas y estudiadas por nosotros y nuestros visitantes. Pero hay que empezar alguna vez y creo que el presente es el más propicio para ello ${ }^{24}$.

Cabe preguntarse por qué no lo hicieron antes, siendo Villacorta ministro en las anteriores administraciones y estando su hijo formándose como Inspector de Museos en Estados Unidos, en el Flint Museum de Chicago. En todo caso, un lapso de 14 años en el que desaparecieron del espacio público el museo y todas sus colecciones, parece altamente sospechoso ${ }^{25}$.

22 Resulta interesante conocer las múltiples publicaciones que escriben padre e hijo, Carlos y Antonio Villacorta, véase, Villacorta, 1927; 1930, casi todos ellos impresos en la Tipografía Nacional que Villacorta como Ministro de Educación controlaba.

23 Enrique Gordillo considera que durante esta etapa Villacorta utilizó los conocimientos arqueológicos que procedían de las diferentes excavaciones internacionales para valorizar el pasado indígena y exaltar el mestizaje, algo similar a lo que había hecho Justo Sierra en México. Sin embargo, a mi juicio había otros intereses de concesiones arqueológicas a Instituciones internacionales como la Carnegie o Universidades norteamericanas como Filadelfia, Pensilvania o Princeton, que obstaculizaron la creación del Museo, con el fin de ganar tiempo para sustraer buena parte de las excavaciones de esa época. Véase, Gordillo, 2001: 132. Lowe, 2003: $1-96$.

24 Villacorta, abril 1931.

25 Según Fuentes Oliva, 2007, los ministros de educación durante los gobiernos de Orellana, Chacón y Ubico fueron, M. I. Arriola y Abaham Cabrera de 1922 a 1927, Antonio Villacorta en 1927, 1928 y 1931, de modo que parece evidente que conocían el tema en profundidad y eran los responsables de las concesiones y licencias. 
La sección de arqueología del Museo Nacional se inauguró el 28 de junio de 1931, en el salón principal del Parque de La Aurora, con presencia del Subsecretario de Educación Pública, del Ministro de Alemania y del inspector de Arqueología. Se iniciaba así la fundación de un Museo Nacional que, por las enormes riquezas arqueológicas y etnológicas del país y por el brillo de la civilización maya, debería de haber sido uno de los primeros en constituirse de toda la América Latina. Tanto más cuando, para esas fechas, ya se habían hecho múltiples excavaciones nacionales e internacionales, especialmente alemanas y norteamericanas, ya se conocían sitios arqueológicos de la envergadura de Mixco, Iximché26, Utatlán, Zaculeu, Tikal, Uaxactum, El Naranjo, Santa Lucía Cotzumalhuapa y otros muchos más reseñados por el propio Carlos Villacorta, como Inspector de Arqueología, Etnología e Historia, y declarados Monumentos Nacionales. Sin embargo, no había un museo central que pudiera albergar «objetos, piezas o monumentos» procedentes de tales lugares y mucho menos se habían creado museos de sitio, locales o comunitarios ${ }^{27}$.

¿Cómo puede entenderse este cúmulo de fracasos y de ausencias? ¿Cómo puede leerse este descuido o esta falta de voluntad política de los sucesivos gobiernos de volver a poner en marcha un Museo Nacional de Arqueología y Etnología con todos los conocimientos y el riquísimo patrimonio cultural existentes desde la primera década del siglo XX?

Para el Inspector de Arqueología, Carlos Villacorta, según memorándum entregado al Ministro de Educación Antonio Villacorta, la tardía aparición del Museo resultaba bastante inexplicable. Dado que Guatemala era «cuna de la más alta civilización indígena de siglos y riquísima en joyas arqueológicas y de la época colonial», la explicación solo podía deberse a «que por descuido no habían sido recogidas metódicamente ni estudiadas en su mayor parte» ${ }^{28}$.

Algo que resulta demasiado simple y poco meditado. Tanto más cuanto Villacorta padre e hijo conocían las excavaciones existentes, habían declarado monumentos nacionales buena parte de los sitios arqueológicos y sabían, además, dónde se encontraban las piezas del anterior museo.

Para responder de forma más ajustada a la cuestión anterior nos parece de enorme importancia un hecho que ha pasado desapercibido hasta el momento:

26 Sobre el tema de la función de los museos de sitio, como Iximché, véase Castillo, 2011. Un excelente recorrido sobre el papel que jugó el Estado en la reconstrucción del museo de sitio de Iximché y su visión turística y comercial. En la misma línea para México, Castañeda, 1996.

27 Recopilación de Leyes, «Solicitud del inspector de arqueología, etnología e historia», 24 de abril de 1931. Así como Villacorta, n. 3 (Guatemala, septiembre de 1932).

28 Villacorta, septiembre 1932. 
en el año 1922 se firmó el Acuerdo Gubernativo 791 por el que el Presidente José María Orellana y el Ministro de Educación, nombraron Director General del Instituto de Arqueología y Director del Museo Nacional de Guatemala a un norteamericano, William E. Gates ${ }^{29}$. Se trata de un lingüista, arqueólogo y notable coleccionista, que además estaba vinculado al estudio de la teosofía en California, que es de donde procedía su interés por los mayas. Gates recolectó a lo largo de su vida una de las mayores colecciones de manuscritos y de objetos mayas a través de una sociedad privada, The Mayan Society, creada por él mismo en 1921, y después la fue vendiendo en sucesivas subastas públicas. La primera colección de documentos y piezas la vendió a la Universidad de Tulane, en 1924, a cambio de 60.000 dólares y su nombramiento como director del departamento de Estudios Mesoamericanos en dicha universidad; la segunda y más completa colección de manuscritos mayas a Robert Garret, en 1936, riquísimo fondo que con el nombre de Gates-Garret pasó en 1947 a la Universidad de Princeton; y la tercera y última colección fue vendida, después del fallecimiento de Gates, a la Bringham Young University of Provo, Utah ${ }^{30}$.

Según relata Gareth Lowe en su extensa y documentada biografía sobre Gates, este extraño personaje no solo logró que el Ministro de Educación, durante el gobierno de Orellana, le nombrara Director del Museo Nacional y Director del Instituto Arqueología ${ }^{31}$, sino que consiguió además que el gobierno guatemalteco emitiera una ley que le permitía, como director del Museo y del Instituto, controlar todas las excavaciones y sacar al extranjero las piezas que se obtuvieran. Gates, en una carta privada dirigida a su amigo G. B. Gordon, se vanagloriaba «de haber logrado aprobar una ley que le permitía sacar el

29 Fundamentamos esta opinión en el hecho de que durante el gobierno de Orellana se emitieron dos acuerdos gubernativos, el 791 del 14 de julio de 1922 y 1925, en el primero, se nombra la Dirección General de Arqueología y Etnología e Historia, y director del Museo Nacional a William E. Gates, cargo adscrito a la Secretaría de Educación. Aparentemente, en este decreto se regulan las excavaciones por parte de universidades extranjeras, sin autorización del gobierno, y se prohíbe la extracción de piezas arqueológicas fuera del país. No obstante, la existencia de dicho reglamento y el nombramiento de un norteamericano coleccionista de piezas mayas, a tenor de los documentos encontrados en esta investigación, fue la etapa de mayor expolio del país. Lowe, 2003: 29.

30 Véase Basler y Wright, 2008. Gordillo, 2001: 138. Lowe, 2003: 45.

31 En su correspondencia privada le cuenta a Gordon cómo se las arregló para ser nombrado director del Instituto y del Museo y así poder controlar los fondos arqueológicos mediante una ley que copiaba al Museo de El Cairo, que le daba todas las atribuciones y poderes para decidir sobre el patrimonio arqueológico, «You will see that (The law) it not only fixed clearly the part and rights of incomimg expeditions, but that the whole direction and control is placed with me as a Director General» (Gates, 1923) en Lowe, 2003: 45. 
$100 \%$ de las piezas al extranjero sin otro control más que el de su propia autorización como Director General» ${ }^{32}$.

Este hecho enfureció al Instituto Carnegie y a Silvannus Morley porque suponía dejarles sin el control de las excavaciones. Se produjo entonces una correspondencia cruzada entre ellos y el secretario del Museo Nacional, acusándose mutuamente de falta de ética y de expolio al país. Después de dos años de fuerte descalificación mutua ante el gobierno de Guatemala y las instituciones norteamericanas, terminó triunfando Morley, a quien el Ministro de Educación le entregó varias licencias para excavar y controlar en su totalidad los sitios arqueológicos de Piedras Negras, Uaxactum, Tayasal y Quiriguá. Hecho que a su vez enfureció a Gates que tildaba al ministro guatemalteco de traidor y corrupto y a sus compañeros norteamericanos de expoliadores del patrimonio guatemalteco ${ }^{33}$.

Después de varios ensayos de contraatacar en Estados Unidos al Instituto Carnegie y, en especial a Morley, así como de intentar llevar a cabo la construcción del museo en Guatemala con piezas de diferentes museos internacionales, Gates fracasó y abandonó la dirección del museo (que durante este breve período, entre 1922 y 1926, tuvo su sede oficial en la antigua iglesia de El Calvario). En su correspondencia, declaró responsables del fracaso a sus enemigos de la Carnegie, a quienes no interesaba que hubiera un Museo Nacional guatemalteco para poder continuar con el expolio arqueológico. Se retiró entonces a su finca de Virginia y realizó el primer sale, en palabras suyas, de su colección mexicana ${ }^{34}$.

Estos hechos explican de forma mucho más convincente el desinterés del Estado, del Ministro de Educación y del propio director del museo en ponerlo en marcha, así como el lapso de diez años que se produce entre la funda-

32 Por la importancia del hecho transcribimos el párrafo de su biógrafo en inglés «Gates further explain the benefits of the law he has got passed; It would permit expeditions to split the finds with the Museo (instead of, as then, taking 100 per cent out of the country) with the permission and supervision of the Direccion General (Gates himself), which he felt would be an even better situation than in Egypt». Carta de Gates a Gordon (1923), en Lowe, 2003: 48 .

33 Lowe, 2003: 11. Carta de Gates a Sinforoso Aguilar: «Morley get a permit we get nothing, and I'm discredited». Al considerar que estaban pasando por encima de su autoridad, Gates renunció al cargo y el Instituto Carnegie y las universidades norteamericanas ganaron así la partida y se hicieron con el control de todas las excavaciones, obteniendo para ello contratos y licencias exclusivas.

34 «Im making my 1924 sale. I simply made a clearence of Mexcian from mid Oaxaca north, retaining Yucatan, Central America and Zapotec link». Lowe, 2003: 13. En esta simple frase podemos observar el carácter mercantilista de Gates. 
ción legal del Museo por Decreto 791 de 1922 y su fundación efectiva en $1931^{35}$.

Por las explicaciones que da el Inspector de Monumentos Carlos Villacorta, la creación efectiva del nuevo Museo Nacional tuvo mucho que ver con las gestiones del Ministro alemán, Wilhelm von Kuhlmann, quien además de sufragar buena parte de los costos, donó «copias de las piezas mayas» de Santa Lucía Cotzumalguapa, cuyos originales estaban en el Museo de Berlín, y de otras piezas de Uaxactum, Quiriguá y Piedras Negras, cuyos originales habían sido cedidos por medio de contratos y licencias exclusivas a Silvannus Morley y se encontraban, según el informe del propio Inspector de Monumentos, «en el Museo de Filadelfia, Pensilvania o Washington». Por esta razón Carlos Villacorta decidió hacer un catálogo fotográfico, para documentar su existencia y denunciar el expolio producido durante los años en que precisamente su padre había sido Ministro de Educación y le correspondía velar por la conservación del patrimonio ${ }^{36}$.

Lo que es evidente es que hasta 1931 no se refundó el Museo Nacional de Arqueología y Etnología y la dirección de Arqueología. Fue Carlos Villacorta quien inició la recolección de piezas dispersas por muy diferentes lugares, quien hizo un catálogo de los sitios arqueológicos y de las piezas del museo, clasificó los objetos, realizó las colecciones de fotografías y formó una biblioteca arqueológica, todo lo cual le dio al Museo el carácter de un verdadero Museo Nacional. Sin embargo, Villacorta en ningún momento hace referencia en sus discursos a que una de las funciones del museo sea la de forjar una memoria o una identidad nacional; para él el objetivo parece reducirse a mostrar la riqueza arqueológica del pasado maya y, según confiesa en el discurso de inauguración, "[a]brigamos la firme creencia de que dentro de poco tiempo y con el apoyo del supremo gobierno y de la sociedad en general el Museo Nacional de Guatemala será factor importante en la vida cultural de la nación» ${ }^{37}$.

35 La biografía y la correspondencia privada de personajes como Gates, brindan mucha información, desconocida hasta el momento, que puede dar luces para entender el retraso en la construcción del nuevo museo.

36 Villacorta, septiembre 1932. En esta memoria queda claro el enorme volumen del tráfico hacia el exterior de piezas mayas que se produjo entre 1917, cuando tuvo lugar el terremoto, y 1931, fecha en que se intentó recuperar las piezas dispersas por diferentes fincas y conventos, así como recuperar —al menos «las reproducciones»- de las que habían salido del país y llevadas a los museos norteamericanos y alemanes, con el permiso de los gobiernos y ministros de educación de turno, en este caso el señor Villacorta y el señor Cabrera. Sin duda ésta parece ser una de las causas del «retraso provocado en su restitución».

37 Villacorta, mayo 1932. 
En 1932, el Ministro Antonio Villacorta entrega un diploma a la Institución Carnegie y a todos los arqueólogos que formaron parte de la investigación por «todos los méritos y el espíritu de solidaridad que les anima». Afirma que «todos los pueblos viven espiritualmente de sus tradiciones y recuerdos» y se hace «necesario fortalecer el alma nacional, aprovechar todos los recursos. Y poner al alcance de las presentes generaciones el cúmulo de noticias en arqueología, en historia, en artes autóctonas que posee Guatemala, para que tengan conciencia de lo que valieron nuestros ancestrales y no desconfíen del porvenir». Y añade a continuación un fragmento muy ilustrativo de lo que Luis Gerardo Morales llama, para el caso de México, un «museo patria»: «Entre nuestras instituciones, es la del Museo Nacional, la llamada a desempeñar un papel importantísimo en la divulgación de lo que fueron nuestros antepasados. Y está cumpliendo, en la medida de sus posibilidades esa misión $»^{38}$.

Es uno de los escasos discursos que contienen un cierto matiz nacionalista, de ver el pasado para comprender el presente y construir el futuro y que hace referencia a la necesidad de exaltar el pasado «de nuestros ancestros para fortalecer el alma de la nación ${ }^{39}$. Esta llamada a recuperar el pasado prehispánico de la nación es de los pocos discursos nacionalistas que podemos encontrar en su obra y son escasos los documentos de Villacorta y de otros intelectuales de la época en que se perciba ese lenguaje museográfico de corte nacionalista. Si bien es verdad que, unas líneas más adelante, añade que el museo será un buen atractivo para el turismo, objetivo que ya desde entonces parece ser el primer interés del Estado guatemalteco en cuanto a museología se refiere.

Durante la llamada Revolución de 1944, el Museo de Arqueología y Etnología se trasladó del salón central — llamado Salón del Té- al Salón 5 de la Finca La Aurora (1946), que sigue siendo su sede, como una dependencia del Instituto de Antropología e Historia y se inauguró oficialmente el 17 de septiembre de 1948, bajo la dirección de Antonio Tejada Fonseca, del director del Instituto de Antropología, Adolfo Molina, y de Robert Smith, delegado de la Institución Carnegie.

En esta segunda inauguración del museo en el siglo XX, se agradeció a las instituciones extranjeras, Carnegie, Pensilvania y la Fundación Rockefeller el apoyo técnico del Dr. Paul Nesbit, quien colaboró en la reestructuración del museo. Las mejoras de esta nueva instalación del museo consistieron en una ampliación del recinto, mayor número de salas y de piezas, entre ellas las donadas por las mencionadas universidades norteamericanas y por Erwin Dies-

38 Villacorta, junio 1932.

39 Idem. 
seldorf (que había cedido su colección privada), así como las procedentes de nuevos hallazgos en Kaminaljuyú, Quiriguá, Uaxactum, Petén y Copán. Es importante resaltar que se dio mucha importancia a la sección de etnología y, por primera vez, se empezó a vincular a los mayas del pasado con los indígenas del presente mostrando sus industrias, artesanías, trajes indígenas y piezas artísticas como parte de un pasado común. Otro hecho novedoso fue la rotación de piezas que se hacía con el fin de poder mostrar buena parte de las reservas museográficas que había en la bodega ${ }^{40}$.

La presencia de intelectuales y antropólogos de nuevo cuño, como Antonio Goubaud, Joaquín Pardo, Adolfo Molina, Hugo Cerezo y David Vela, muchos de ellos pertenecientes a las primeras redes de indigenistas del país, hizo que el Museo empezara a articular el pasado con el presente de los mayas y a buscar una unidad y un hilo conductor en la historia social y cultural del país y que por primera vez aparezcan documentos en donde se hable de forjar una «verdadera nacionalidad», como una de las funciones del Museo Nacional ${ }^{41}$.

\section{PARTE. LA PATRIMONIALIZACIÓN DE LA CULTURA Y LA PRIVATIZACIÓN DEL PATRIMONIO NACIONAL: DOS CARAS DE LA MISMA MONEDA (1960-2010)}

¿Qué significa «patrimonialización de la cultura»por parte de las elites de poder? Entendemos el término como el proceso por el cual los sectores oligárquicos se apropian en el siglo XIX del Estado, de la tierra y la cultura y la consideran un bien propio, que hay que conservar porque representan los bienes espirituales de la nación y son «el alma de la nación» ${ }^{42}$.

El patrimonio histórico-cultural de una nación lo deciden las clases dominantes y es necesario teatralizarlo en conmemoraciones, monumentos y mu-

40 En El Imparcial se publica una noticia con los cambios y mejoras del museo, así como las donaciones de los museos de México y de Nueva York. Ya allí se habla de 15.000 piezas guardadas en los sótanos por la falta de espacio para exhibirlas. En la descripción de la exposición ya se observa un lenguaje museográfico diferente y una interrelación entre pasado y presente. Sobre la reforma y reubicación del museo durante el periodo revolucionario, véase $E l$ Imparcial, 11 de septiembre de 1948 y 17 de septiembre de 1948.

41 Goubaud Carrera, 19 de octubre de 1937; 26 de octubre de 1937 y 29 de octubre de 1937. Casaús Arzú, 2011. Gutiérrez Mendoza, 2010.

42 Lo decía Villacorta con esas mismas palabras. Con las excavaciones y posicionamientos de las academias internacionales los historiadores y arqueólogos guatemaltecos tuvieron que hacer un esfuerzo y aceptar el pasado maya como parte del patrimonio nacional, de ahí la necesidad de Villacorta de apropiarse de ese pasado, pero no del presente de «los indios degenerados actuales», los cuales no formaban parte de la nación ni del alma nacional. Gordillo, 2001 . 
seos. Para García Canclini esa teatralización del patrimonio «es un esfuerzo por simular que hay un origen y una sustancia fundante» de nuestra identidad, por lo que hay que conservar, catalogar y enseñar un repertorio de bienes simbólicos que forman parte de «nuestro pasado» y en ese pasado, según lo definían los estados oligárquicos y las dictaduras liberales de Guatemala, no estaban los indios, por eso debían estar fuera de la historia y de los museos ${ }^{43}$.

Para García Canclini, lo que se define como patrimonio e identidad pretende ser el reflejo fiel de la «esencia nacional», de ahí su teatralización y presentación en conmemoraciones, exposiciones universales, monumentos, plazas palacios museos etc. ${ }^{44}$. Ser culto o tener cultura supone conocer un repertorio fijo y prescrito de objetos valiosos que han sido catalogados para ser expuestos en un museo y si no se encuentran en él, no es un descuido, como opinaba el Inspector de Monumentos y Director del Museo Nacional, Carlos Villacorta, hay una intencionalidad consciente o inconsciente de lo que debe de ser exhibido o no.

De modo que esta dejación del Estado para decidir qué forma parte de su patrimonio histórico-cultural y qué no, está muy presente en la tardía formación de un Museo Nacional de Arqueología y Etnología y el hecho de que la Sociedad Económica de Amigos del País (SEAP) fuera la que se adueñara del patrimonio histórico-nacional indica que son las elites intelectuales a las que les corresponde apropiarse, guardar y conservar el patrimonio de la nación. Ese imaginario racial, así como la desconfianza de las elites económicas en la capacidad del Estado de preservar el patrimonio, sumado al profundo desprecio y discriminación hacia los pueblos indígenas descendiente de los mayas, provocó una escasa presencia estatal en la preservación del patrimonio nacional, dejando a las instituciones extranjeras, universidades norteamericanas en su mayoría, a la iniciativa privada, patronatos de empresas nacionales y centroamericanas, el control casi absoluto del patrimonio cultural hasta la actualidad.

Ello nos permite explicar el porqué buena parte de las mejores piezas y repertorios arqueológicos se encuentran en manos de grupos familiares que llevan a cabo un proceso de teatralización del patrimonio cultural, poniéndolo en escenarios propios, «sus museos» dentro de sus fábricas y otras propiedades, desde el siglo XIX hasta la actualidad.

43 Resulta sintomático que en el libro Azul de la dictadura de Estrada Cabrera en donde se muestran todos los monumentos, bellezas exóticas, industrias y un sinnúmero de bienes simbólicos del país no exista ni una sola mención a un Museo Nacional durante los veinte años de dictadura liberal.

44 García Canclini, 1989: 151 y ss. 
No es casual que el primer museo fundado por la SEAP estuviera en la sede de su institución; que la finca donde se encuentran parte de las ruinas de Kaminaljuyú fuera propiedad, en el siglo XIX, del diputado e historiador Antonio Batres Jáuregui y ahora aloje al Museo Miraflores, en el terreno propiedad de la inmobiliaria Spectrum, de la familia Herrera; que el Museo Ixchel del Traje Indígena y el Museo Popol Vuh se encuentren en terrenos propiedad de la Universidad privada Francisco Marroquín; que un parque arqueológico como el de El Mirador de la Fundación Pacuman (Patrimonio Cultural y Natural Maya) se encuentre en la cementera de la familia Novella, con apoyo de las familias Paiz y Castillo y de dos Fundaciones norteamericanas, FARES y Global Heritage Foundation; o que el Museo de Arte Precolombino y del Vidrio Moderno se encuentre sito en el Hotel Casa Santo Domingo, propiedad de Edgar Castillo.

Todos ellos siguen siendo fundaciones privadas de coleccionistas individuales, ubicadas en lugares de difícil acceso y de casi imposible presencia de público masivo, por el entorno y por el efecto simbólico de entrar en áreas restringidas, prohibidas para «el vulgo». Por ello parece interesante estudiar no solo el origen de dichos museos y de sus propietarios, sino el espacio físico que ocupan los museos y la escasa importancia que el Estado ha dado a la política patrimonial, a la función didáctica de los museos y a la formación de la memoria nacional.

Por ello nos vamos a centrar en esos museos y parques arqueológicos privados como casos paradigmáticos de patrimonialización cultural y de teatralización de la cultural nacional, por parte de las elites nacionales e internacionales y, a la vez, observar que también dentro de la museografía privada existen marcadas diferencias en cuanto a la forma, los objetivos y el contenido de los museos de arqueología y, que no todos los museos privados tienen un afán exclusivamente esteticista y/o de ritualización histórico-antropológica, desvinculados del presente de los pueblos indígenas y de sus interconexiones entre el pasado y el presente. Algunos poseen una función pedagógica y social y una museografía moderna y didáctica; pero de lo que adolecen todos estos museos que a continuación vamos a presentar, es de una visión nacionalista que invoque la recuperación de una memoria histórica y de una visión nacional ${ }^{45}$.

45 Esta falta de visión nacional o de «reencantamiento nacionalista», posiblemente, se deba a que esa etapa del «museo templo» o el «museo-patria» ya había pasado y debía de haberse promovido a fines del XIX o principios del XX. No se produjo ni por parte del Estado ni de las elites intelectuales, como puede verse en el proceso de formación del Museo Nacional ni en los discursos de las elites intelectuales del momento, tal y como sucedió en México. Véase el caso mexicano, Morales, XXVIII (México, 2007): 37. 
La patrimonialización de la cultura en los museos y fundaciones privadas de Guatemala

En los años 1960 surgió un interés especial en las redes familiares guatemaltecas por formar colecciones sobre el pasado maya y el pasado colonial para adornar sus casas de la Antigua Guatemala o de la capital. En determinado momento éstas se convirtieron en casas-museos que, por las condiciones de seguridad del país, no podían ser visitadas ni siquiera por los estudiosos del tema. Debido al incremento de objetos prehispánicos y coloniales de estos coleccionistas o al fallecimiento sin herederos de estas familias, decidieron crear sus propios museos privados, dentro de sus empresas, fábricas, hoteles o fincas, para que pudieran ser visitadas sin temor a sufrir un secuestro o robo de sus colecciones, ya que, por esa época, empezaba a haber un interés generalizado en Estados Unidos y en Europa sobre la cultura maya y se iniciaba un importante tráfico de objetos mayas hacia el extranjero.

Uno de los primero museos que surgió bajo este contexto de museo privado o museo colección-gabinete, es el de Jorge y Ela Castillo Valenzuela, una de las colecciones privadas más espectaculares, con más de 3.000 piezas de primera magnitud, lo que incluye la mejor colección de incensarios mayas. La pareja Castillo Valenzuela, sin descendencia, donó a la Universidad privada Francisco Marroquín toda su colección en 1978. El Museo estuvo ubicado en un edificio de la avenida de la Reforma de la capital hasta que la universidad creó unas dependencias propias en 1997, en donde se inauguró con el nombre de Museo Popol Vuh. En el mismo recinto se ubicaba una segunda colección, especializada en trajes mayas, que había cedido otra pareja de coleccionistas, León y Carmen Petersen, formándose así el Museo Ixchel, cuyo nombre proviene de la diosa maya de la fecundidad y del tejido: Ixchel.

La donación de ambas colecciones privadas a esta universidad también privada se produce por las mismas fechas, 1977. Ambas colecciones cuentan con un patronato formado por personalidades guatemaltecas y norteamericanas, en el caso del Museo del traje, Friends of the Ixchel Museum es una fundación compuesta en su mayoría por socios, directores o patrocinadores norteamericanos, siendo escasa la presencia de familias guatemaltecas, destacando nombres como Hemstead y Smith — de origen inglés - vinculados a la agricultura cafetalera en Cobán. Esta fundación lleva a cabo exposiciones de los textiles mayas por Estados Unidos, con las indumentarias representadas en acuarelas o expuestas sobre maniquíes descontextualizados de sus etnias, simplemente como piezas folklóricas, sin que exista una descripción histórico-cosmogónica de la vestimenta de los pueblos indígenas ni una vinculación con la identidad 
de las mujeres mayas actuales y, mucho menos, un estudio ideográfico de los huipiles.

El boletín informativo del museo hace hincapié en el colorido de los trajes, la utilización de diferentes tintes y materiales, en la variedad de los telares y tejidos, y en las exposiciones temporales donde se exhiben cuadros y fotografías de una gran belleza pictórica, pero con escasa relación con la realidad social del país. Como proyecto social de la fundación se promueve una escuela de jóvenes tejedoras indígenas que aprenden a utilizar el telar, los colores y los materiales tradicionales ${ }^{46}$.

Podríamos decir en palabras de García Canclini, que la teatralización de este museo tiene una finalidad absolutamente folklórica y estetizante y su función es atraer al turista hacia el folklore y el colorido de Guatemala, no en balde uno de los lemas del museo es «un mundo de color» ${ }^{47}$. Siguiendo los trabajos de García Canclini, Morales o Bustamante y Quijada, la museografía de este espacio no solo representa al «indio petrificado», sino a «la india vestida, colorida y pintada» como un retrato fijo de una realidad inmóvil, bella y perfecta, en donde la pobreza, el sufrimiento o la fealdad, son inconcebibles e inexistentes.

El Museo Popol Vuh, sin llegar a ese nivel de esteticismo folklórico, muestra exclusivamente los objetos mayas como parte de una historia y de una arqueología del pasado, con todo lujo de información y periodización, clasificando todos los objetos según los periodos arqueológicos del arcaico, preclásico del 1500 A.C. al clásico tardío y postclásico 1500 D.C., sin hacer ninguna mención a la vida de los pueblos mesoamericanos ni a sus relaciones productivas, artísticas o religiosas, centrándose, exclusivamente, en el aspecto arqueológico o artístico del objeto, sin plantear un enlace con el presente de los pueblos indígenas o mayas.

Aquí «el indio petrificado del pasado» cobra una relevancia espectacular, pero incluso «ese indio del pasado» se encuentra deshistorizado y no tiene nada que ver con el presente de los pueblos mayas. Solo en la introducción aparece una mención muy clara «a los pueblos antiguos de Guatemala», para que no quede ninguna duda de que esos pueblos dejaron de existir y que nada tienen que ver con el presente de los pueblos mayas. Es más, el único presente que liga con ese pasado, es el pasado colonial, que viene a completar y a enriquecer «el arte guatemalteco».

En todo el catálogo de este museo no hay una sola mención a los mayas del presente, ni a los mayas como parte del acervo cultural y mucho menos, como

46 Knoke de Arathoon y Miralbés Polanco, 2003.

47 Idem. 
«nuestros antepasados». No existe la más mínima apropiación de ese pasado legendario, como si la civilización maya hubiera muerto con el colapso arqueológico del siglo IX y fuera posteriormente sustituida por el arte colonial.

Esta percepción museográfica estática y a su vez ideológica como la máxima representación de la patrimonialización y arqueologización del poder de las elites y de la civilización maya, como parte de un pasado muerto, «mayas sí pero indios no» ${ }^{48}$, nos recuerda al debate de los intelectuales de 1937 para los que, según uno de los historiadores más emblemáticos del momento, Pedro Pérez Valenzuela, frente a los argumentos de Gándara Durán y de Goubaud, que clamaban por la incorporación plena de los indígenas como ciudadanos a la nación, sostenía las siguientes premisas y argumentaciones:

Los indígenas carecen de cultura y civilización porque se encuentran en decadencia a la llegada de los españoles y además son una raza inferior.

No se puede llamar cultura o civilización a la producción de los indígenas cuando no conocían la rueda, ni los animales domésticos. Ni creer que el Popol Vuh es un libro literario cuando «no es más que una sarta de inventos y divagaciones ineptas sin doctrina coherente». No digamos la escritura y los glifos que no son más que «una serie de muñecos y dibujos sin sentido».

Los indígenas carecen de una religión y son paganos e idólatras. Fueron los españoles los «que vinieron a darles un alma al cristianizarlos, porque la nueva religión que les brindaban era la antítesis de la suya, esa sí cruenta y feroz, esa sí aniquiladora del espíritu».

Los indígenas carecen de nacionalidad porque los pueblos bárbaros y salvajes no pueden adquirirla porque nunca tuvieron tierras, al no existir propiedad privada, porque carecen de cultura y civilización y, por último, porque fue la Colonia la que mejoró su situación, gracias al legado de España que les dio una religión, un alma, un territorio y «que fundió su sangre con la sangre decadente del indígena» ${ }^{49}$.

Esta mentalidad arcaica, decimonónica y obsoleta, parece estar subyacente en el enfoque museográfico de estas colecciones privadas de objetos representados exclusivamente como piezas arqueológicas y artísticas, sin que parezca existir la más mínima posibilidad de hilvanar pasado con presente y de evocar el pasado para construir una memoria común.

48 Véase el artículo de Cecilia Méndez, 1996, sobre las elites peruanas que aceptaban su pasado incaico, como parte de la construcción nacional, pero no el indígena quechua de la actualidad.

49 Pérez Valenzuela, 1937. Sobre este tema, véase, Casaús Arzú, 2008a. 


\section{El Museo Miraflores}

El origen de este museo, a pesar de su reciente creación (2002) y de su patrocinio por parte de la iniciativa privada, posee otras características que le hacen diferente tanto en su concepción, como en su lenguaje museográfico y en sus funciones. Su nombre y sus orígenes datan de los descubrimientos arqueológicos hechos por la Universidad de Pensylvania y del Instituto Carnegie de la antigua ciudad de Kaminaljuyú, cuyas ruinas estaban ubicadas en la Finca Miraflores, propiedad privada del historiador liberal Antonio Batres Jauregui $\mathrm{y}$, tras su muerte, de otros propietarios que decidieron construir una zona de viviendas residenciales. Tanto el arqueólogo Juan Antonio Valdés como otros arqueólogos guatemaltecos y estadounidenses pusieron mucho esfuerzo en restaurar las piezas arqueológicas y en proteger el sitio en donde se encon$\operatorname{traban}^{50}$.

El proyecto Miraflores II creció enormemente debido a que los hallazgos arqueológicos cubrían un área muy extensa, de ahí que, a iniciativa de los arqueólogos y de la empresa constructora Spectrum, se planteara la idea de construir un museo de sitio dentro de la urbanización, teniendo como base la colección de piezas encontradas en el área, la llamada colección Miraflores y respetando los montículos y espacios en donde se encontraban las ruinas arqueológicas.

El Instituto de Antropología e Historia - IDAEH-, el Ministerio de Cultura y la empresa constructora, llegaron al acuerdo de construir un «museo de sitio» al interior de la urbanización, «con el fin de cooperar con la educación y la cultura de los Guatemaltecos» y de respetar el espacio de las ruinas de Kaminaljuyú y así evitar que las piezas arqueológicas descubiertas fueran a parar a las bodegas del Instituto.

El acuerdo firmado en diciembre de 1995, planteaba que el diseño, la construcción y la administración del museo correrían a cargo de la empresa propietaria, Spectrum ${ }^{51}$ y el Ministerio de Cultura aportaría el terreno. Bajo Acuerdo Ministerial 323-95, se iniciaron los trabajos de construcción del museo. La idea de los arquitectos y arqueólogos fue plantear un espacio amplio, con una zona de ocio y un jardín arqueológico en donde estuviera ubicado el museo, con espacios diáfanos en donde los visitantes pudieran recorrer tanto el inte-

50 Véase Valdés, Hatch, 1996. Kaplan y Valdés, 2004: 77-86.

51 Spectrum es una empresa inmobiliaria de la familia Herrera, que se dedica al desarrollo de proyectos inmobiliarios creada en 1995 en Guatemala. Entre otras cosas la empresa tiene la administración del Paseo Miraflores y del Museo Miraflores, y a ellos se debe la construcción del Centro Comercial y el Paseo de Miraflores al lado del museo. 
rior como el exterior y visitar los montículos de la antigua ciudad de Kaminaljuyú. Un diseño adecuado a la museografía moderna, según Valdés ${ }^{52}$, que combinara el quehacer educativo con la diversión y en donde las funciones de preservación, estudio y comunicación estuvieran articuladas. Para Valdés preservar ese espacio y posibilitar su conocimiento a un público amplio con una buena guía de comunicación representaban los objetivos para la construcción de un guión museográfico de carácter temático y dinámico que permitiera tener una perspectiva general sobre cómo y quiénes eran los hombres y mujeres que ocuparon ese valle, cuáles eran sus ocupaciones, su producción, la agricultura y sistemas de irrigación, sus contactos comerciales y sus expresiones artísticas, sin olvidar los vestigios de esas civilizaciones en el presente de los pueblos mayas.

El Museo permite hacer un recorrido interior y exterior a través del uso de grandes vitrales en donde se ven los montículos y maquetas reconstruidas de la ciudad de Kaminaljuyú, con el apoyo de paneles giratorios y películas que van exponiendo los diferentes periodos históricos y muestran cómo vivían los habitantes de la ciudad y cómo era la sociedad, a través de vitrinas con objetos que muestran la vida cotidiana. En otra sala se presentan las ceremonias religiosas de Kaminaljuyú, así como el comercio y su relación con otras regiones lejanas como México, El Salvador y Honduras. Por último, se muestra todo el trabajo de excavaciones y la importancia de preservar el patrimonio cultural y ambiental de la región. Las exposiciones temporales permiten ligar el presente con el pasado y las similitudes artísticas entre las culturas ancestrales y las manifestaciones artísticas actuales.

¿Qué es lo que queremos resaltar de este museo? Que cuenta, como los otros museos de arqueología, con financiación privada y para más inri, de una empresa inmobiliaria de una de las redes familiares más importantes de Guatemala. Sin embargo, no todos los museos con financiación privada tienden a patrimonializar la cultura ni a apropiarse del pasado y la memoria, como cuestión exclusiva de un grupo o una clase.

Si las sociedades o fundaciones que financian un museo privado dejan a los técnicos, museógrafos o profesionales para que diseñen con toda libertad, conocimiento y profesionalidad lo que representa el pasado y la memoria histórica de los pueblos, y si ese proceso de conservación y preservación de un pasado no se encuentra teñido de un afán de patrimonializar la cultura o de invisibilizar al otro, sino de darle la palabra y mostrar sus expresiones culturales y artísticas y de mostrar el entorno cultural y medioambiental en donde se pro-

52 Moscoso, 2001. Valdés, 2003. 
dujeron dichas culturas, y además la función del museo va encaminada a lo que el arqueólogo y diseñador del museo, Juan Antonio Valdés, catalogó como las tres funciones de un museo moderno: preservar, estudiar y comunicar, bienvenida sea la financiación privada, con objeto de preservar y ampliar el patrimonio nacional. Pero si la finalidad de los museos es mantener esos conocimientos para beneficio de una elite y con criterios de patrimonialización cultural o simplemente estetizantes, es cuando el Estado debería intervenir para evitar esa apropiación cultural de un pasado histórico en beneficio de unos pocos o para controlar la función y el lenguaje museográfico de dicho museo.

A nuestro juicio, el lenguaje museográfico del Museo Miraflores reúne todas las características de un museo arqueológico moderno y la financiación privada ha evitado que todas esas piezas cayeran en el olvido o fueran enterradas en las bodegas del IDAEH, sin que el público tuviera acceso a ellas y sin la posibilidad de preservar buena parte de un patrimonio histórico nacional, ya sea por la incapacidad y falta de voluntad del Estado o por la escasa financiación del mismo. El Museo de Miraflores y la preservación de la ciudad de Kaminaljuyú es un buen ejemplo a tener en cuenta para futuros «museos de sitio» en América Central, sin que suponga ningún expolio para el país.

La Cuenca de El Mirador y el Museo Carlos F. Novella: Sala Cuenca El Mirador

La iniciativa de la Cuenca Mirador, como proyecto global de carácter arqueológico, cultural y medioambiental para la promoción y preservación del área del mismo nombre, surge a iniciativa de un arqueólogo de la Universidad de Idaho, Richard Hansen, que en 1980 encuentra, al norte del Petén, a pocos kilómetros de México, el mayor descubrimiento arqueológico de fines del siglo XX. Una superficie de más de $2.128 \mathrm{~km}^{2}$ con más de 200 sitios arqueológicos, de los cuales diez son mayores que Tikal, un conjunto del preclásico tardío maya de una riqueza inestimable. A juicio de Hansen y de otros arqueólogos y antropólogos nacionales, se trata del mayor conjunto urbano del continente americano, con unos templos de una dimensión mayor que cualquier otro de las civilizaciones europeas y americanas de la antigüedad ${ }^{53}$.

53 Richard Hansen es un arqueólogo de la Universidad de Idaho que descubre el sitio de El Mirador, siguiendo el rastro de otros viajeros y arqueólogos de principios de siglo que habían estado en esa región, y se da cuenta de que estos sitios datan del Preclásico Tardío maya, lo que introducen un cambio sustancial en la presencia temprana de los mayas en el Petén y al florecimiento de su cultura. Es el principal impulsor de este proyecto de preservación cultural y am- 
La importancia del descubrimiento, la escasa atención prestada por los sucesivos gobiernos, más los intereses de las industrias madereras que están desforestando toda la región y la fuerte presencia del narcotráfico en la zona, llevó a Richard Hansen a crear la Fundación Pacunam ${ }^{54}$, con la ayuda de algunas familias como los Novella, Paiz y Berger, con el fin de preservar el patrimonio cultural y ambiental de la Cuenca de El Mirador, y poder conseguir financiamiento privado de dichas empresas con la finalidad de seguir la exploración de los principales complejos arqueológicos, como La Danta o El Tigre, y sobre todo para evitar la depredación de la cuenca.

La Fundación PACUNAM, Patrimonio Cultural y Natural Maya, cuenta con una serie de aliados estratégicos como Foundation for Anthropological Research and Environmental Studies -FARES — ${ }^{55}$ cuyo presidente es el arqueólogo Richard Hansen, su director es Mel Gibson y el director ejecutivo François Berger, que lo son además de la Global Heritage Foundation (GHF), situada en California y cuyo objetivo es la preservación de sitios culturales. Según la revista de la GHF, esta fundación ha donado «más de 5 millones a Pacunam en los últimos seis años y ha recibido más de 2 millones de dólares de 13 compañías y familias $\rangle^{56}$. En la revista publicada por FARES encontramos unas menciones de agradecimiento a aquellos colaboradores que hayan contribuido con más de 250.000 dólares al año, entre los que se encuentran FARES, PACUNAM, Global Heritage y Hilda Cofiño de Herrera, que reciben la condecoración del Jade de Diamantes; entre aquellos que colaboran con más de 100.000 dólares, reciben el Jade de Platino, y son las familias de los Berger,

biental de la Cuenca de El Mirador, Presidente de FARES y el mayor promotor de esta iniciativa, ha publicado innumerables artículos especializados sobre el tema.

54 El director de Pacunam es otro miembro de las grandes familias guatemaltecas, Fernando Paiz, y en el directorio de Pacunam se encuentran las redes de los Novella, Berger y Dorión.

55 FARES firma, en el 2006, con el Departamento del Interior de Estados Unidos y el gobierno de Guatemala durante la presidencia de Berger, otro miembro de la red familiar de los Berger Dorión, un acuerdo de colaboración para la conservación del patrimonio cultural y ambiental de Guatemala de 10 años, «con el fin de proteger dicha área y de desarrollar "un turismo sustentable"». Además de estas dos organizaciones, FARES y Global Heritage, como aliados estratégicos, se incorporan una serie de fundaciones «sin ánimo de lucro», como Fundación Carlos Novella, Paiz, Pantaleón, Castillo Hermanos, Pacunam y otras multinacionales como Google, National Geographic o la Fundación de Mel Gibson y William Holden. Véase Boletín de FARES, 2006 y 2007-2008. Durante la presidencia de Colon se inaugura un proyecto gubernamental para desarrollar el turismo en la zona, llamada 4 Balam. Uno de los congresistas que aparece liderando esta iniciativa es el candidato presidencial, Manuel Baldizón. Véase FARES, 2007-2008.

56 Véase el artículo sobre la Cuenca de El Mirador, «el apoyo de las trece compañías centroamericanas y de las familias». Brown, mayo 2011. 
Morgan, los Herrera, Cofiño Sthal, además de la fundación Carlos Novella y el Banco Industrial. Toda una serie de empresas privadas y de familias que contribuyen con este proyecto de patrimonialización y privatización de la cultura nacional ${ }^{57}$.

PACUNAM no se encuentra vinculada a ninguna universidad norteamericana, como en el pasado, sino que está estrictamente formada por socios individuales, grupos familiares y empresas privadas nacionales e internacionales, según consta en su página web:

La fundación está constituida por empresarios e individuos de la región, preocupados por el rescate cultural y natural, además de estar dispuestos a actuar de forma contundente en la protección y desarrollo de un crecimiento rentable y sostenible. Actualmente, cuenta con 8 miembros fundadores. Aunque no acepta la participación de organizaciones gubernamentales, trabaja en alianza y cooperación con el Gobierno, ya que busca fortalecer las alianzas público-privadas ${ }^{58}$.

Hasta el momento ha recibido más de tres millones de donaciones privadas de diferentes familias y empresas como los Paiz, Berger, Novella, Casti1lo, Torrebiarte, Herrera, Cofiño Sthal y, según consta en sus declaraciones, recibe el apoyo financiero de las siguientes empresas: Cementos Progreso, Cervecería Centroamericana, Wallmart, Banco Industrial, Blue Oil, Samsung, City Bank, PICA, Madre Tierra, Ingenio Pantaleón, Disagro, Cofiño Stahl y Claro 59

Como socios internacionales se encuentra la Fundación Alberto II de Mónaco y además cuenta con el apoyo del Banco Interamericano de Desarrollo y de la UNESCO para tratar de declarar la Cuenca de El Mirador como Patrimonio de la Humanidad y Reserva Natural.

La declaración de uno de sus socios, miembro de la familia Torrebiarte, parece bastante clara:

57 Véase FARES, 2007-2008: 35.

58 «Pacunam fortalece el magno proyecto "Cuenca Mirador" con tres millones de dólares», 4 de agosto de 2008. Disponible en http://www.deguate.com/artman/publish/turismo noticias/ pacunam-fortalece-el-magno-proyecto-cuenca-mirador-con-tres-millones-de-dolares.shtml. Esta declaración pública de una página web de la fundación PACUNAM nos parece el máximo de la patrimonialización de la cultura nacional, no solo en sentido figurado sino en sentido explícito de apropiación económica del patrimonio de la nación y de sus bienes culturales y territoriales. Nada más y nada menos que de una extensión territorial de más de $2.125 \mathrm{~km}^{2}$, con todo el patrimonio arqueológico del país.

59 Habría que preguntarse, para futuras investigaciones, cuál es el precio que los aliados estratégicos, las empresas privadas y las familias piden a cambio y en qué términos económicos o patrimoniales está fijada la ayuda. 
Pacunam desarrolla planes estratégicos con el fin de atraer más miembros socios para invertir en proyectos de protección y rescate del patrimonio cultural y natural de la región, así como fomentar el desarrollo social y económico por medio de un turismo responsable, sostenible y rentable $\mathrm{e}^{60}$.

A juicio de Gregory Lassalle el proyecto va aún más lejos, se trata de una maniobra de la oligarquía guatemalteca y de la multinacional anglo-francesa Perenco, de explotar y rentabilizar la cultura maya y convertir a El Mirador en un parque temático de turismo de alto standing, las declaraciones de Fernando Paiz y de Mel Gibson así parecen indicarlo. Gibson afirma que se está creando «un nuevo modelo de conservación para sitios arqueológicos y bosques vírgenes», «una estación turística de lujo, de alta gama, no de mochileros. Turistas que bajan en helicóptero desde Cancún, visitan la zona y se van» ${ }^{61}$.

Esta propuesta coincide con el plan del reparto de Petén, denunciado por Insight Crime, por el cual SEGEPLAN ha contemplado el desarrollo del Petén en varias zonas de interés económico: el sur para agro-combustibles, el centro para la producción de electricidad y extracción de petróleo y el norte para el desarrollo de la industria turística y de zonas protegidas ${ }^{62}$. Y nos preguntamos al respecto, ¿qué papel juega el Estado ausente de estas negociaciones y sin una política pública al respecto? Y ¿cuáles son las contrapartes de las «donaciones» de empresas nacionales y extranjeras frente a este nuevo expolio del patrimonio cultural? Son preguntas que nos hacemos y que aún no tienen respuesta ${ }^{63}$.

Para terminar con este apartado acerca de la patrimonialización y privatización de la cultura nos preguntamos, ¿cuál es el museo en el que se exhiben los hallazgos de este parque arqueológico? Podríamos pensar que en el Museo Nacional de Arqueología y Etnología, pero no es así. Debido a la falta de espacio, de interés o a las pugnas internas, buena parte de estas piezas se encuentran en el museo privado de la Familia Novella, situado en las inmediaciones

60 «Pacunam fortalece el magno proyecto "Cuenca Mirador" con tres millones de dólares», 4 de agosto de 2008. Disponible en www.deguate.com (fecha de consulta: noviembre 2011). La declaración es de José Miguel Torrebiarte, citado en Lasalle, 2011.

61 Lassalle, 2011.

62 Dudley, 2011 y «Grupos de poder en Petén, Territorio política y Negocios», 2011.

63 A juicio del principal impulsor de este proyecto el Dr. Richard Hansen, la finalidad es lograr la preservación de la zona y evitar que las industrias madereras o el narcotráfico se apoderen de esta región y para ello es necesario contar con todo el apoyo nacional e internacional por el enorme costo que tiene su preservación. A su juicio, dichas familias y empresas no reciben ninguna contraprestación a cambio de su ayuda y la estrategia de investigación recae sobre FARES, fundación que él preside. Entrevista realizada por correo electrónico a Richard Hansen, 8 de noviembre de 2011. 
de la Fábrica Cementos Progreso, en la casa de uno de los fundadores de la fábrica, Carlos F. Novella, que dejó su residencia para que se convirtiera en un museo que mostrara el desarrollo de la gran industria cementera guatemalteca a través de la biografía de su fundador. El museo cuenta en diferentes salas la historia de la fábrica, desde fines del siglo XIX y a lo largo del siglo XX, haciendo énfasis en las fases de desarrollo de dicha industria. Se podría decir que es un museo de familia que expone las sucesivas etapas de la industria familiar hasta la muerte de su fundador.

En este museo de carácter industrial, ubicado a las afueras de la ciudad, se abre una nueva sala con un buen número de piezas arqueológicas del preclásico maya, con osamentas, cráneos y objetos múltiples, cuya finalidad «es mostrar la historia de la Cultura Maya, conservando el pasado y construyendo el futuro de la Cuenca del Mirador» ${ }^{64}$. O la reciente exposición presentada en el Museo Quai Branly de París sobre la Cuenca del Mirador, financiada por todas estas firmas y por la petrolera anglo-francesa Perenco ${ }^{65}$.

Este hecho, así como el origen de la fundación Pacunam y sus «aliados estratégicos», nos da una idea de que en el caso de algunos museos privados de arqueología, fundados en el último tercio del siglo XX, no solo obedecen a una patrimonialización de la cultura sino a una privatización del patrimonio cultural de la nación. Con un silencio cómplice o un desinterés del Estado por estos hechos, lo que demuestra una vez más, el escaso control estatal en la preservación de su patrimonio nacional ${ }^{66}$.

\section{El Museo de Arte Precolombino y del Vidrio Moderno}

Este museo lo fundó en 1998 uno de los mayores coleccionistas de piezas arqueológicas y coloniales, Edgar Castillo Sinibaldi (Cush), al que va dedicado el museo y sin duda la persona que donó buena parte de la colección, «el hombre que tuvo la visión».

64 Véase catálogo del Museo Carlos Novella, Sala Cuenca del Mirador. Resulta bastante inexplicable la relación entre un museo biográfico familiar de carácter industrial y una sala de arqueología maya. La explicación que nos dieron es que el hijo de Carlos Novella, Enrique Novella, fue uno de los fundadores de la Fundación Pacunam, que gestiona la Cuenca del Mirador, este a instancias de Richard Hansen, ofreció su museo familiar para que se exhibieran las piezas de la Cuenca. Estos objetos se encuentran en calidad de préstamo y proceden del Museo de Arqueología, previo permiso del Ministerio de Cultura.

65 Lassalle, 2011.

66 Se intentó realizar algunas entrevistas a distintas dependencias del Estado de las cuales solo nos fue concedida una con el Director General de Patrimonio Cultural, Erick Ponciano, el 3 de noviembre de 2011. 
Está patrocinado por la empresa familiar de su fundador Cervecería Centroamericana, S.A., de Guatemala y Vidriera Guatemalteca, con el sponsor de Cervecería de Costa Rica, S.A., y Vitro, S.A., de México.

La idea del fundador es establecer un museo de carácter estético en donde dialoguen «los objetos de arcilla precolombina, por un lado, con el vidrio moderno, por el otro». El pasado se integra con el presente por medio del arte. Las similitudes se muestran a través de contrastes de colores y formas, «en un lenguaje universal que sobresale bellamente». En buena parte del catálogo se hace referencia a que la única función estética es mostrar como «la unidad estética brota de los dos mundos distintos y separados de la existencia humana». En el catálogo se insiste en que las similitudes fueron buscadas y no mandadas hacer, lo que demuestra que el hombre desde hace más de 2.000 años se ha inspirado en los mismos temas.

El Museo se encuentra situado en las ruinas del convento de Santo Domingo en la Antigua Guatemala convertido en hotel de alto estándar bajo cesión del gobierno a los dos propietarios, Edgar Castillo y Jorge Castañeda. El objetivo principal de este museo es mostrar el pasado glorioso, pero acabado, de los mayas a través de una visión esteticista, comparando los objetos de la antigua cultura americana con piezas de vidrio francesas como Daum, Bacarrat o Lalique, o piezas de la vidriera nacional con el fin de mostrar las enormes «similitudes» de objetos que, al margen de su denominación (animales, joyería, figura humana), poco o nada tienen que ver entre sí y poco o nada sirven para explicar el pasado y el presente de los pueblos mayas, como no sea para constatar «la modernidad y universalidad» de los mayas al realizar dichas figuras.

El museo se divide en varias salas en donde se exponen diferentes temáticas relacionadas con el color, el diseño, la forma humana o animal, la joyería, como referentes de similitud y de contraste entre dos culturas universales: la francesa y la maya. Volviendo al carácter estetizante y universalista del museo, en la sala dedicada a exhibir el color, diseño y la forma se menciona que: «el hombre reconoce dos clases de belleza: la natural y la artística, y lo que busca es el elemento que le proporciona placer estético». Las comparaciones y similitudes se muestran de una forma simple, ahistórica y descontextualizada y en ningún momento se hace mención a la cultura de los pueblos mayas del presente.

Podríamos sintetizar el lenguaje museográfico de este museo como eminentemente estetizante y enajenante, en cuanto despoja y aleja al objeto en cuestión de su cultura y su entorno, con el fin de comparar el pasado con la cultura del vidrio actual y, además, de elevar la categoría del vidrio centroamericano a la de un objeto artístico, no solo de consumo. 
En general consideramos que este museo adolece de cualquier función social o pedagógica, no hay una sola mención al pasado y al presente de los mayas. Los objetos son universales y pueden ser comparados con cualquier otra cultura, de allí su valor, pero las similitudes son totalmente ahistóricas, extemporáneas y carecen de razón de ser. El valor que tienen las piezas está en función de un aspecto estrictamente estético. Solo en la parte final del catálogo hay alguna mención histórica de las piezas y, por supuesto, el Estado está ausente de todo el catálogo.

Consideraciones generales sobre los museos privados de arqueología y etnología

El proceso de patrimonialización cultural en el caso de Guatemala pareciera que data de un hábito o una forma de entender la cultura elitista desde el siglo XIX, cuando la Sociedad Económica de Amigos del País se hizo cargo del primer Museo de arqueología, zoología y mineralogía del país, en la década de 1860.

No hay ningún atisbo en los gobiernos liberales de construir un museo nacional ni de valorar el pasado prehispánico como parte de la nación homogénea; más bien hay un desinterés o una falta de voluntad política del Estado por contribuir a conformar una nación homogénea con la presencia de las culturas que formaban parte del pasado histórico del país.

Hay una ausencia manifiesta de un nacionalismo museográfico y de un orgullo nacional de pertenecer a un pasado glorioso, como el de los mayas, tanto que para algunos intelectuales los mayas nunca tuvieron una cultura, los jeroglíficos no eran más que «una serie de muñecos y dibujos sin sentido» y el Popol Vuh, «una sarta de inventos y divagaciones ineptas sin doctrina coherente».

Esta percepción del pasado hizo que el Estado y buena parte de la intelectualidad de los años 1930 y 1940 despreciaran la cultura indígena y no tuvieran en cuenta para nada el patrimonio nacional. Podría decirse que buena parte de la intelectualidad asumió la máxima de «indios no, pero mayas tampoco», no aceptándolos ni siquiera como parte de los museos nacionales.

Fueron las elites académicas norteamericanas y europeas, a principios del siglo XX, las que se hicieron eco del gran pasado histórico de los mayas y de la extraordinaria riqueza arqueológica del país. No solo llamaron la atención internacional y nacional, sino que de paso se apropiaron de buena parte de las riquezas arqueológicas que de esa manera fueron a parar a instituciones nor- 
teamericanas o a museos europeos sin que hubiera ningún control por parte del Estado guatemalteco de este expolio.

Los tres últimos gobiernos de Guatemala en el siglo XX han contribuido notablemente a prolongar esta situación, concediendo licencias, contratos $\mathrm{y}$ nombramientos a intelectuales y universidades norteamericanas para ocupar puestos públicos de relevancia y favoreciendo, de esa manera, la cesión del patrimonio arqueológico nacional y el expolio del país.

Podemos afirmar que a lo largo del siglo XX ha habido una cierta connivencia del Estado con algunas elites intelectuales nacionales para encubrir el expolio, cuando no una colaboración en estas tareas, además de un cierto colonialismo interno. Lo que hizo posible el nombramiento como director del $\mathrm{Mu}-$ seo Nacional de un norteamericano, William E. Gates, que resultó ser uno de los más grandes «exportadores» de manuscritos y piezas arqueológicas mayas a Estados Unidos, vendiendo su colección privada a distintas universidades como Tulane, Princeton y Utah.

Fue durante el gobierno del general Ubico cuando se tomaron medidas más efectivas y se concretaron decretos que prohibían el expolio del patrimonio nacional. Y también cuando se llevó a cabo la refundación del Museo Nacional de Arqueología y Etnología.

Fue la generación de 1920, especialmente los protoindigenistas, la que hizo hincapié en la necesidad de controlar y preservar el patrimonio cultural de los mayas y de su cultura, especialmente el antropólogo Antonio Goubaud Carrera, director del Instituto Indigenista, fundador de la Revista Guatemala Indige$n a$ y uno de los intelectuales que más luchó por la preservación del pasado maya vinculándolo con el presente de los pueblos indígenas.

Existe una larga experiencia histórica de prácticas sociales y políticas, por parte de las elites de poder de patrimonializar la cultura y de privatizar el patrimonio nacional, que se inicia en el siglo XIX y se perpetúa hasta el siglo XXI. Esa patrimonialización puede explicarse como un proyecto histórico que les coloca como los dueños del patrimonio cultural de la nación, ya sea por la falta de interés y voluntad del Estado y sus respectivos gobiernos de intentar negociar una memoria y una historia que contribuyan a forjar la identidad nacional o también puede explicarse, como en el caso de Honduras y de Perú, por los enormes intereses de los centros académicos y arqueológicos internacionales de apropiarse del patrimonio de las culturas americanas, como un patrimonio universal con el fin de que sea expuesta en «sus museos coloniales», como trofeo de las metrópolis coloniales. En el caso de las excavaciones realizadas en Guatemala por parte de expediciones enviadas por universidades y centros académicos de Estados Unidos, de Alemania y España, en el pasado, así parecen indicarlo. 
Esta patrimonialización de las elites de poder ha provocado que los museos de arqueología y antropología privados posean las mejores piezas de la cultura maya y que buena parte del legado histórico de la civilización maya esté en manos de grupos de la iniciativa privada, que lo utiliza como una manera de hacer propaganda para sus propias empresas, y que con frecuencia forman parte de consorcios internacionales, con lo cual no se sabe a dónde irá a parar finalmente el patrimonio arqueológico de la nación.

En Guatemala los museos privados de arqueología no solo no constituyen «el alma de la nación» como en México, Argentina o Brasil, sino que se sitúan fuera de la historia y de la memoria, como se puede ver por el debate mantenido en 1937, sobre qué hacer con las cátedras de arqueología y antropología o con los museos y, sobre todo, el lugar que deben de ocupar «los indios» como sujetos fuera de la historia y de la memoria de la nación.

La máxima expresión de esta patrimonialización y privatización del patrimonio nacional la tenemos en el proyecto turístico y de desarrollo sostenible de la Cuenca de El Mirador, en donde se desconoce el acuerdo al que se ha llegado con las autoridades de los sucesivos gobiernos y las contraprestaciones que han adquirido todas estas empresas familiares e internacionales a cambio de sus donaciones, poniendo en grave riesgo la protección arqueológica y ambiental de más de $2.128 \mathrm{~km}^{2}$ y más de 200 sitios arqueológicos.

Por todo ello podemos concluir que, por parte del Estado y de las elites existe un desinterés en relación a una de las funciones básicas de los museos referente a dotar de una visión nacional o identitaria a los museos de arqueología de Guatemala. De modo que, la función y el valor de los museos que en su día tuvieron el propósito de educar a la ciudadanía mostrando su pasado histórico y su cultura y, a su vez, contribuir a crear una memoria y una identidad nacional, está ausente en este tipo de museos privados para convertirse en un puro objeto estetizante y como mucho un reclamo de atracción turística. Con ello lo que se logra es deshistorizar el pasado, desdibujar la cultura nacional, crear un falso espejismo de «modernidad» y «universalidad de las culturas» y no contribuye, en nada, a construir una identidad nacional.

La escasa presencia del Estado y su escaso interés de proteger el patrimonio nacional ha provocado que la práctica más usual de colaborar con los gobierno de turno sea mediante la cesión o concesión del patrimonio cultural y artístico de la nación sin contraprestaciones, permitiendo que históricamente se haya producido y se continúe produciendo un permanente expolio de las riquezas naturales y artísticas de la nación, justo un modelo contrario al nacionalista implantado por países como México, Argentina o Brasil. 


\section{REFERENCIAS BIBLIOGRÁFICAS}

Andermann, Jens (coord.), Relics and Selves: Iconographies of the National in Argentina, Brazil and Chile (1880-1890), London, Bickbech College, The Iberoamerican Museum of Visual Culture, 2000. Disponible en www.bbk.ac.uk/ibamuseum (fecha de consulta: noviembre de 2011).

Basler, Teresa T. y Wright, David C., «The Making of a Collection: Mesoamerican Manuscripts at Princeton University», Libraries \& the Cultural Record, vol. 43, n. ${ }^{\circ} 1$ (2008): 29-55.

Blanco, Ramón, «Estudio de la Civilización Maya», El Imparcial, Año XV, 5047 (Guatemala, 26 de junio de 1936).

Brown, Chip, «Probing the Mysteries of The Mayan», Smithsonian Magazine, mayo, 2011.

Bustamante, Jesús, «Museos, memoria y antropología a los dos lados del Atlántico. Crisis institucional, construcción nacional y memoria de la colonización», Revista de Indias, 254 (Madrid, 2012), en este número.

Casaús Arzú, Marta, «El gran debate historiográfico de 1937 en Guatemala: "Los indios fuera de la historia y de la civilización". Dos formas de hacer historia», Revista Complutense de Historia de América, vol. 34 (Madrid, 2008a): 209-231.

Casaús Arzú, Marta, «Vasconcelos y los debates sobre el indígena y la nación en Guatemala», Cuadernos Americanos, Nueva Época n. ${ }^{\circ}$ 124, abril-junio, 2008b: 109-127.

Casaús Arzú, Marta, «El binomio degeneración-regeneración en el positivismo y espiritualismo de principios del siglo XX», Marta Casaús Arzú (coord.), El lenguaje de los ismos: algunos conceptos de la modernidad en América Latina, Guatemala, F\&G editores, 2010a: 157-202.

Casaús Arzú, Marta, «El debate sobre el indio y la nación en la década de 1930 en Guatemala: El dilema entre nacionalizar o indigenizar la nación (1920-1940)», Antonio Escobar Ohmsted, Romana Falcón y Raymund Buvé (eds.), La arquitectura histórica del poder, nacionalismo y estados en América Latina, siglos XVIII, XIX y XX, México, Colegio de México, Centro de Estudios Históricos y Centro de Estudios y Documentación Latinoamericano, 2010b: 59-93.

Casaús Arzú, Marta, «Goubaud Carrera en la red de antropólogos guatemaltecos de la Generación de 1920», 2011. Disponible en http://uam.academia.edu/MartaECasausArzu/Papers/457047/El_papel_de_mediacion_de_Antonio_Goubaud_en_la_antropologia_guatemalteca, 2011.

Casaús Arzú, Marta y García Giráldez, Teresa, Las redes intelectuales centroamericanas: un siglo de imaginarios nacionales (1820-1920), Guatemala, F\&G editores, 2005. 
Castañeda, Quetzil E., In the Museum of Maya Culture: Touring Chichen Itza, Minneapolis, University of Minnesota Press, 1996.

Castillo, Carlos Rafael, Iximché, lugar de memoria de Guatemala, la contribución de la arqueología de la identidad, Tesis de Maestría, Guatemala, FLACSO, abril, 2011.

Dudley, Steven, «Los Zetas en Guatemala», Insight Crime, 8 de septiembre de 2011.

Earle, Rebecca, The return of the native: Indians and myth-making in Spanish America, 1810-1930, Durham, Duke University Press, 2007.

El Imparcial, «Esplendor aborigen, Nuevo Museo de Arqueología está por inaugurarse», El Imparcial, Año XXVII, n. ${ }^{\circ}$ 9, 115 (Guatemala, 11 de septiembre de 1948).

El Imparcial, «Instituto de Antropología: Centro Honra de Nuestra Cultura», El Imparcial, XXVII, n. ${ }^{\circ}$ 9, 119 (Guatemala, 17 de septiembre de 1948).

Fuentes Oliva, Regina, El proyecto social y politico durante el gobierno de Lázaro Chacón a través del estudio de un fragmento de redes sociales, Tesis de Grado, Licenciatura en Historia, Escuela de Historia, Universidad de San Carlos de Guatemala, 2007.

FARES, Foundation for Anthropological Research and Environmental Studies, Annual Report, 2006.

FARES, Foundation for Anthropological Research and Environmental Studies, Annual Report, 2007-2008.

García Canclini, Nestor, Culturas hibridas, estrategias para entrar y salir de la modernidad, Barcelona, Grijalbo, 1989.

Gordillo, Enrique, «Hacia la formación del "alma nacional": José Antonio Villacorta Calderón y la historia de Guatemala (1915-1962)», Marta Casaús Arzú y Óscar Peláez Almengor (eds.), Historia intelectual de Guatemala, Guatemala, CEUR-USAC, UAM, AECI, 2001: 119-167.

Goubaud Carrera, Antonio, «La creación de la facultad de antropología, historia y etnología», El Imparcial, Año XV, n. 5.056 (Guatemala, 7 de julio de 1936).

Goubaud Carrera, Antonio, «Discusiones Historiográficas: La Fábula Maligna», El Imparcial, Año XVI, n. ${ }^{\circ} 5.450$ (Guatemala, 19 de octubre de 1937).

Goubaud Carrera, Antonio, «Contribución al conocimiento del indio. Estudios Necesarios y Humanización del Indio», El Imparcial, Año XVI, n. ${ }^{\circ} 5.456$ (Guatemala, 26 de octubre de 1937).

Goubaud Carrera, Antonio, «Contribución a la historia del indio guatemalteco, sus aspectos antropológicos», El Imparcial, Año XVI, n. ${ }^{\circ} 5.459$ (Guatemala, 29 de octubre de 1937). 
«Grupos de poder en Petén, Territorio política y Negocios», Insight Crime, Guatemala, julio, 2011. Disponible en www.plazapublica.com.gt (fecha de consulta: noviembre 2011).

Gutiérrez Mendoza, Edgar, Antropologistas y antropólogos: una generación, Guatemala, Universidad de San Carlos, Instituto de Investigaciones Históricas, Antropológicas y Arqueológicas, 2000.

Gutiérrez Mendoza, Edgar, Ensayos sobre pensamiento antropológico (Guatemala y Brasil), vol. 1, Guatemala, Escuela de Historia, USAC, 2009.

Gutiérrez Mendoza, Edgar, «La propuesta de fundación de una "Facultad Universitaria de Antropología, Arqueología, Historia y Etnología" en 1936», $14 .^{\circ}$ Encuentro de Latinoamericanistas Españoles, Santiago de Compostela, 2010.

Helaine Silverman (ed.), Arqueological site Museums in Latin America, Florida, University Press of Florida, 2006.

Kaplan, Jonathan y Valdés, Juan Antonio, «Chocola, an Apparent Regional Capital in the Southern Maya Preclassic: Preliminary Findings of the Proyecto Arqueológico Chocola (PACH)», Mexicon 26 (4), 2004: 77-86.

Knoke de Arathoon, Bárbara y Miralbés Polanco, Rosario, Guía del Museo Ixchel del traje indígena, Guatemala, Fundación para el desarrollo del Museo Ixchel, 2003.

Lassalle, Gregory, «En Guatemala la oligarquía rentabiliza la civilización Maya», en Le monde diplomatique en español, junio de 2011, disponible en www.monde-diplomatique.es (fecha de consulta: noviembre 2011).

Levin, Amy K. (ed.), Defining Memory, Local Museums and the construction of History in America's Changing Comunities, EE.UU., Altamira Press, 2006.

Lowe, Gareth W., Register of the Biography of William E. Gates, 1863-1940, L. Tom Perry Special Collections, Brigham Young University, 2003.

Luján Muñoz, Luis, «El Primer Museo Nacional de Guatemala (1866 1881)», Anales de la Sociedad de Geografía e Historia de Guatemala, 46 (1973): 173-189.

Méndez, Cecilia, «Incas sí, indios no: apuntes para el estudio del nacionalismo criollo en el Perú», Lima, IEP (Documentos de Trabajo n. ${ }^{\circ}$ 56), 1996.

Morales, Luis Gerardo, «Ojos que no tocan: la nación inmaculada», Fractal, n. ${ }^{\circ} 31$ (2003): 49.

Morales, Luis Gerardo, «Museológicas, problemas y vertientes de la investigación en México», Relaciones XXVII/111, (Zamora, 2007): 31-66.

Moscoso, Fernando, «Museos para la paz: Un nuevo concepto de museo histórico en Guatemala», en XIV Simposio de Investigaciones Arqueológicas en Guatemala, 2000 (editado por J. P. Laporte, A. C. Suasnávar y B. Arroyo), Museo Nacional de Arqueología y Etnología, Guatemala, 2001: 942-948. 
Pérez Valenzuela, Pedro, «Los Indígenas durante la Conquista y la Colonia», El

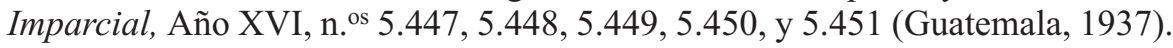

Quijada, Mónica; Bernand, Carmen y Schneider, Arnd, Homogeneidad y Nación. Con un estudio de caso, Argentina, siglos XIX y XX, Madrid, CSIC, 2001.

Recopilación de Leyes, «Solicitud del inspector de arqueología, etnología e historia», 24 de abril de 1931.

Sierra Valle, Alfredo, «Iniciativa Factible: La Institución de una cátedra para el Estudio de la Historia maya», El Imparcial (7 de julio de 1936).

Valdés, Juan Antonio y Hatch, Marion Popenoe, «Evidencias de poder y control social en Kaminaljuyú: Proyecto Arqueológico Miraflores II», IX Simposio de Investigaciones Arqueológicas en Guatemala, 1995 (editado por J. P. Laporte y H. Escobedo), Guatemala, Museo Nacional de Arqueología, 1996: 377-396.

Valdés, Juan Antonio, «El Museo Miraflores: Un punto de encuentro en Kaminaljuyú», en XVI Simposio de Investigaciones Arqueológicas en Guatemala, 2002 (editado por J. P. Laporte, B. Arroyo, H. Escobedo y H. Mejía), Guatemala, Museo Nacional de Arqueología y Etnología, 2003: 863-870.

Villacorta, Antonio, «La Institución Carnegie de Washington y la Sociedad de Geografía e Historia de Guatemala: Disertación en respuesta al discurso del Sr. Oliver Ricketson Jr., en nombre de la Institución Carnegie», Anales de la Sociedad de Geografía e Historia de Guatemala, tomo 9, n. ${ }^{\circ}$ 2, junio de 1932: 135-157.

Villacorta, Carlos, «Memorial al presidente Ubico y al Ministro de Educación», Revista del Museo Nacional de Guatemala, n. ${ }^{\circ}$ 1, Guatemala, 13 de abril de 1931.

Villacorta, Carlos, «Alocución del inspector de arqueología, etnología e historia Carlos A. Villacorta en el acto de inaugurase el salón de arqueología del museo nacional de Guatemala el 28 de julio de 1931», Revista del Museo Nacional de Guatemala, n. ${ }^{\circ}$ 2, mayo de 1932: 20.

Villacorta, Carlos, «Memoria presentada al Ministro de Educación Pública de las labores correspondientes al Museo Nacional de Arqueología en el segundo semestre de 1931», Revista del Museo Nacional de Guatemala, n. ${ }^{\circ}$ 3, septiembre de 1932.

Villacorta, Carlos y Villacorta, Antonio, Arqueología guatemalteca, Guatemala, Tipografía Nacional, 1927.

Villacorta, Carlos y Villacorta, Antonio, Codices Mayas reproducidos y desarrollados, Guatemala, Tipografía Nacional, 1930.

Fecha de recepción: 13 de septiembre de 2011.

Fecha de aceptación: 15 de diciembre de 2011. 


\section{National Museum and private museums in Guatemala: patrimony and patrimonalization. A century of attempts and frustrations}

During the $19^{\text {th }}$ century most Latin American countries promoted the foundation of national museums (containing their own archeology, anthropology, and ethnology) as a means of fostering state building and laying the foundations for the homogenization of the nation. Such institutions sought to promote the civic education of the citizenry, the recovery of memory and the construction of a common past allowing for the formation of a national identity. The case of Guatemala, however, stands out for its uniqueness and its tendency to go in the opposite direction: to deny the Maya past, not to accept the principle of a homogeneous nation, and to leave the foundation of the first National Musem, in the $19^{\text {th }}$ century, in the hands of the Sociedad Económica de Amigos del País. The construction of archeological museums was later left to private initiative, thereby generating a process of patrimonalization of culture and, at the same time, a privatization of the national patrimony.

KeY WORDS: National Museum; public Museum; private museum; memory, patrimony; nation; Guatemala. 